\title{
Article \\ The Stacy-G Class: A New Family of Distributions with Regression Modeling and Applications to Survival Real Data
}

\author{
Lucas D. Ribeiro Reis ${ }^{+}\left(\mathbb{D}\right.$, Gauss M. Cordeiro ${ }^{+}\left(\mathbb{D}\right.$ and Maria do Carmo S. Lima ${ }^{*},+(\mathbb{D}$
}

check for updates

Citation: Reis, L.D.R.; Cordeiro, G.M.; Lima, M.d.C.S. The Stacy-G Class: A New Family of Distributions with Regression Modeling and Applications to Survival Real Data. Stats 2022, 5, 215-257. https:// doi.org/10.3390/stats5010015

Academic Editor: Wei Zhu

Received: 4 February 2022

Accepted: 2 March 2022

Published: 4 March 2022

Publisher's Note: MDPI stays neutral with regard to jurisdictional claims in published maps and institutional affiliations.

Copyright: (C) 2022 by the authors. Licensee MDPI, Basel, Switzerland. This article is an open access article distributed under the terms and conditions of the Creative Commons Attribution (CC BY) license (https:// creativecommons.org/licenses/by/ $4.0 /)$.
Department of Statistics, Federal University of Pernambuco, Recife 50710-165, Brazil; ldrr1@de.ufpe.br (L.D.R.R.); gauss@de.ufpe.br (G.M.C.)

* Correspondence: maria@de.ufpe.br

† These authors contributed equally to this work.

\begin{abstract}
We study the Stacy-G family, which extends the gamma-G class and provides four of the most well-known forms of the hazard rate function: increasing, decreasing, bathtub, and inverted bathtub. We provide some of its structural properties. We estimate the parameters by maximum likelihood, and perform a simulation study to verify the asymptotic properties of the estimators for the Burr-XII baseline. We construct the log-Stacy-Burr XII regression for censored data. The usefulness of the new models is shown through applications to uncensored and censored real data.
\end{abstract}

Keywords: Burr-XII distribution; gamma-G family; regression; simulation study; Stacy distribution

\section{Introduction}

In the last decades, there has been an increasing interest of articles in the context of new distributions. The ideas behind the generation of new families and, consequently, new distributions, are the most diverse possible, due to the transformation of a cumulative distribution function (cdf) to an integral of a probability density function (pdf) with an upper limit function, which follows some conditions [1]. However, even with the advancement in the area and the large number of publications, it is necessary to propose new distributions that fit more satisfactorily to real datasets. In this sense, our main objective is to study the properties of a new family that can present better fits to real data when compared to well consolidated classes.

The method of adding extra shape parameters to a cdf to generate more flexible distributions has been investigated by several authors over the last 20 years. The cdf of the generalized gamma (GG) pioneered by [2] is

$$
F_{\mathrm{S}}(w)=\frac{\gamma\left(a / b,(c w)^{b}\right)}{\Gamma(a / b)}, \quad w>0,
$$

where $c>0$ is a scale parameter, $a>0$ and $b>0$ are the shape parameters, $\Gamma(a)=$ $\int_{0}^{\infty} t^{a-1} \mathrm{e}^{-t} d t$ is the complete gamma function, and $\gamma(a, z)=\int_{0}^{z} t^{a-1} \mathrm{e}^{-t} d t$ is the lower incomplete gamma function. The generalized gamma model is also known as the Stacy distribution, say $\mathrm{S}(a, b, c)$. Table 1 lists some of its special cases.

de Pascoa et al. [3] defined the Kumaraswamy-Stacy, which extends the KumaraswamyWeibull [4], exponentiated-Stacy [5], exponentiated Weibull [6], among others. The betaStacy is another generalization introduced by [7], which includes 25 sub-models. Bourguignon et al. [8] proposed the truncated Stacy and showed that its hazard rate function (hrf) has five different shapes. Prataviera et al. [9] defined the odd log-logistic-Stacy (OLLS) distribution, which allows bathtub-shaped and unimodal hrf, and proposed a heteroscedastic log-OLLS regression to censored data. Ortega et al. [10] derived diagnostic measures to the Stacy regression, and [11] addressed this regression for long-term survivors. 
Table 1. Stacy special distributions.

\begin{tabular}{cccc}
\hline Distribution & $\boldsymbol{a}$ & $\boldsymbol{b}$ & $\boldsymbol{c}$ \\
\hline Gamma & - & 1 & - \\
Weibull & $b$ & $a$ & - \\
Exponential & 1 & 1 & - \\
Rayleigh & 2 & 2 & $1 / 2$ \\
Chi-square & $n / 2$ & 1 & $1 /(k \sqrt{2})$ \\
Half-normal & 1 & 2 & $1 /(k \sqrt{2})$ \\
Maxwell & 3 & 2 & \\
\hline
\end{tabular}

Several families in the literature have emerged from well-known distributions, and provide more flexibility to the generated distributions, such as: odd log-logistic [12], Kumaraswamy [13], new extended-G [14], odd power Lindley [15], extended Weibull-G [16], Marshall-Olkin generalized G Poisson [17], generalized two-sided [18], generalized odd Weibull [19], odd log-logistic logarithmic [20], exponential Lindley odd log-logistic-G [21], odd Lomax [22], and odd Chen-G [23], among others. Two published distributions based in two previous families are: Kumaraswamy power Lomax [24] and odd log-logistic Birnbaum-Saunders-Poisson [25]. Some other classes based on the logarithmic transformation are the type I half-logistic [26], Gompertz [27], Weibull Marshall-Olkin [28], and xgamma [29].

Setting $c=1$ in the $S(a, b, c)$ distribution, we define the cdf of the Stacy-G (SG) family (for a given parent $\mathrm{G}$ ) by changing the argument $w$ by the baseline $\operatorname{cdf} G(x ; \eta)$ with a $q$-vector of parameters $\eta$

$$
F_{\mathrm{SG}}(x)=\frac{\gamma\left(a / b,\{-\log [1-G(x ; \eta)]\}^{b}\right)}{\Gamma(a / b)} .
$$

By differentiating (1), the SG density reduces to

$$
\begin{aligned}
f_{\mathrm{SG}}(x)= & \frac{b}{\Gamma(a / b)[1-G(x ; \boldsymbol{\eta})]} g(x ; \boldsymbol{\eta})\{-\log [1-G(x ; \boldsymbol{\eta})]\}^{a-1} \\
& \times \exp \left\{-\{-\log [1-G(x ; \boldsymbol{\eta})]\}^{b}\right\},
\end{aligned}
$$

where $g(x ; \boldsymbol{\eta})=d G(x ; \boldsymbol{\eta}) / d x$.

Henceforth, the random variable $X \sim \mathrm{SG}(a, b, \boldsymbol{\eta})$ has density (2). For $b=1$, the SG family becomes the gamma-G class [30]. So, the Stacy family is a generalization of the gamma-G class with an extra shape parameter, thus providing greater flexibility to the density and failure rate functions. For $\delta=a / b$, Equation (2) is just Equation (10) of [30]. However, the last work does not investigate the structural properties of (2), which are obtained here from a linear representation. Further, a new reparametrization is provided in the context of regression. For $a=b=1$, it reduces to the parent $\mathrm{G}$.

The hazard rate function (hrf) of $X$ is

$$
\tau_{\mathrm{SG}}(x)=\frac{b g(x ; \boldsymbol{\eta})\{-\log [1-G(x ; \boldsymbol{\eta})]\}^{a-1} \mathrm{e}^{-\{-\log [1-G(x ; \eta)]\}^{b}}}{\left\{\Gamma(a / b)-\gamma\left((a / b),\{-\log [1-G(x ; \boldsymbol{\eta})]\}^{b}\right)\right\}[1-G(x ; \boldsymbol{\eta})]} .
$$

We present four special models in Section 2. We derive a useful family density representation in Section 3, and obtain some properties in Section 4. In Sections 5 and 6, we discuss the estimation of the parameters and Monte Carlo simulations, respectively. We define in Section 7 a new log-Stacy-Burr XII (LSBXII) regression. In Section 8, we prove the utility of the new models fitted to three real datasets. Finally, Section 9 concludes the paper.

\section{Special Stacy-G Distributions}

We present below four distributions generated by the Stacy-G family. 


\subsection{Stacy-Burr XII (SBXII)}

Consider the parent Burr XII (BXII) cdf

$$
G_{\mathrm{BXII}}(x)=1-\left[1+(x / s)^{c}\right]^{-d},
$$

where all parameters are positive. The SBXII density (for $x>0$ ) follows from Equation (2) as

$$
\begin{aligned}
f_{\mathrm{SBXII}}(x)= & \frac{b c d^{a}}{s^{c} \Gamma(a / b)} x^{c-1}\left[1+(x / s)^{c}\right]^{-1}\left\{\log \left[1+(x / s)^{c}\right]\right\}^{a-1} \\
& \times \exp \left\{-\left\{d \log \left[1+(x / s)^{c}\right]\right\}^{b}\right\} .
\end{aligned}
$$

The SBXII reduces to the gamma-Burr XII (GBXII) [31] when $b=1$, gamma-Lomax [32] when $b=c=1$, and gamma-log-logistic [33] when $b=d=1$. Clearly, BXII $(a=b=1)$, Lomax $(a=b=c=1)$ and $\log$-logistic $(a=b=d=1)$ are well-known special distributions.

\subsection{Stacy-Uniform (SU)}

Inserting the $\operatorname{cdf} G(x)$ and pdf $g(x)$ of the uniform, say $\mathrm{U}(c, d)$, in Equation (2), the SU density (for $-\infty<c<x<d<\infty$ ) comes as

$$
f_{\mathrm{SU}}(x)=\frac{b}{(d-x) \Gamma(a / b)}\left\{-\log \left(\frac{d-x}{d-c}\right)\right\}^{a-1} \mathrm{e}^{-\left\{-\log \left(\frac{d-x}{d-c}\right)\right\}^{b}} .
$$

It leads to the standard SU distribution when $c=0$ and $d=1$. The uniform $\mathrm{U}(c, d)$ distribution refers to $a=b=1$.

\subsection{Stacy-Chen (SC)}

The cdf and pdf of the Chen distribution (for $x>0$ ) are

$$
G(x ; \lambda, \beta)=1-\mathrm{e}^{\lambda\left(1-\mathrm{e}^{x^{\beta}}\right)} \text { and } g(x ; \lambda, \beta)=\lambda \beta x^{\beta-1} \mathrm{e}^{x^{\beta}+\lambda\left(1-\mathrm{e}^{x^{\beta}}\right)},
$$

respectively, where $\lambda>0$ is a scale and $\beta>0$ is a shape parameter.

Inserting these expressions into Equation (2), the pdf of the SC distribution follows as

$$
f_{\mathrm{SC}}(x ; a, b, \lambda, \beta)=\frac{b \lambda^{a} \beta}{\Gamma(a / b)} x^{\beta-1}\left(\mathrm{e}^{x^{\beta}}-1\right)^{a-1} \exp \left\{x^{\beta}-\left[-\lambda\left(1-\mathrm{e}^{x^{\beta}}\right)\right]^{b}\right\} .
$$

For $b=1$, the SC distribution becomes the gamma-Chen [34] distribution.

\subsection{Stacy-Weibull (SW)}

The cdf of the Weibull (for $x>0$ ) is $G_{W}(x)=1-\mathrm{e}^{-(\beta x)^{\alpha}}$, where $\alpha>0$ and $\beta>0$. The SW density can be expressed as

$$
f_{\mathrm{SW}}(x)=\frac{b \alpha \beta^{a \alpha}}{\Gamma(a / b)} x^{a \alpha-1} \mathrm{e}^{-(\beta x)^{\alpha b}} .
$$

The gamma-Weibull follows when $b=1$, whereas $a=b=1$ refers to the Weibull. The exponential and Rayleigh models are obtained when $a=b=\alpha=1$ and $a=b=1$ and $\alpha=2$, respectively.

Figure 1 reports the above densities for fixed parameters. The two extra parameters provide more flexibility to these densities. Figure 2 gives the hrfs of the SBXII and SW models for specified parameters. For both models, the hrfs can be increasing, decreasing, bathtub, and inverse bathtub, thus showing that the extra shape parameters provide flexibility.

The hrf of the GBXII [31] model can be decreasing, decreasing-increasing-decreasing, and inverse bathtub. The extra parameter $b$ gives the possibility of two other forms for this 
hrf: increasing and bathtub. Hence, the SBXII distribution allows a greater variety of fits to different data sets than the GBXII model.

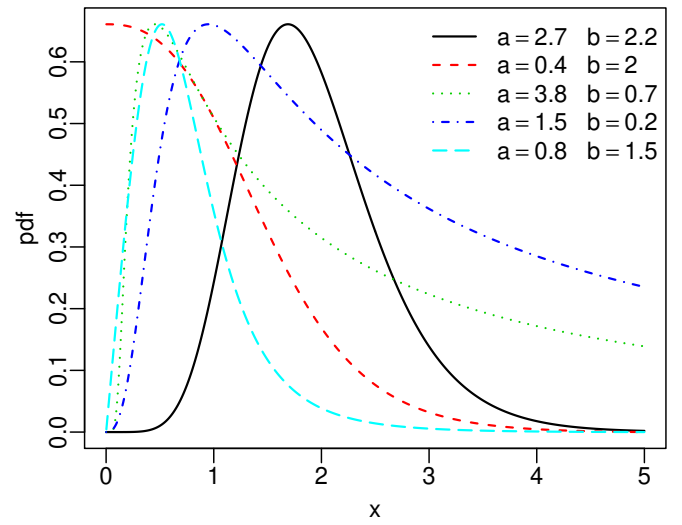

(a)

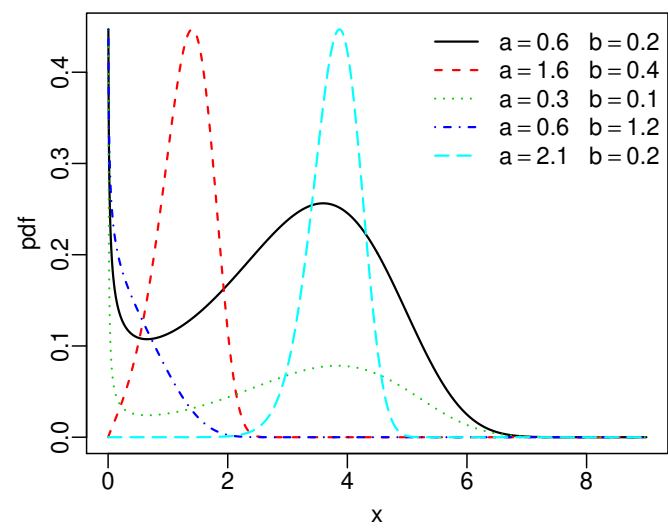

(c)

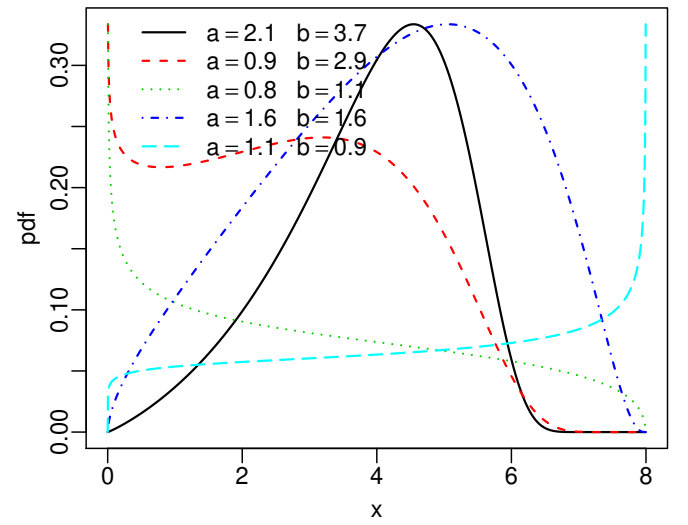

(b)

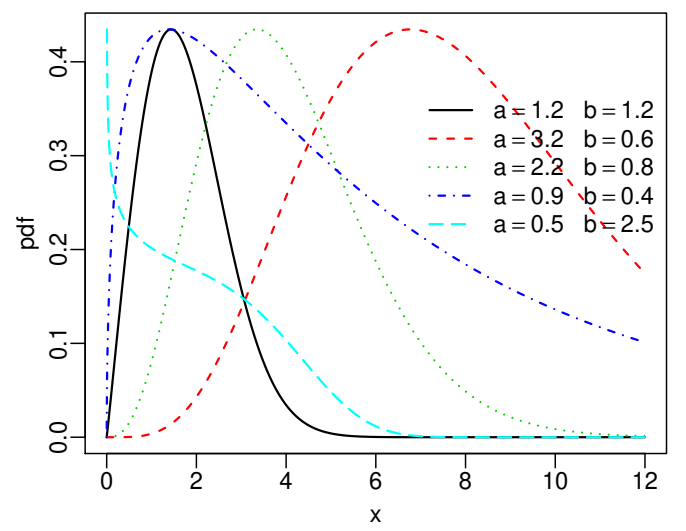

(d)

Figure 1. Special densities: (a) $\operatorname{SBXII}(a, b, 1.2,0.7,2.5)$, (b) $\operatorname{SU}(a, b, 0,8)$, (c) $\operatorname{SC}(a, b, 1.7,1.3)$ and (d) $\operatorname{SW}(a, b, 0.5,1.7)$.

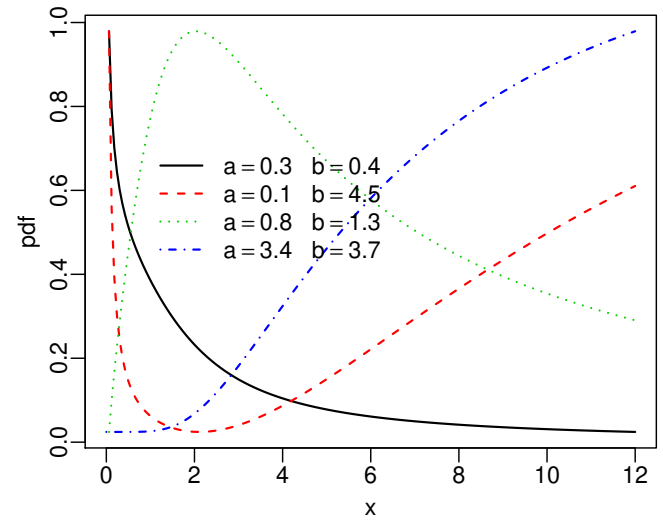

(a)

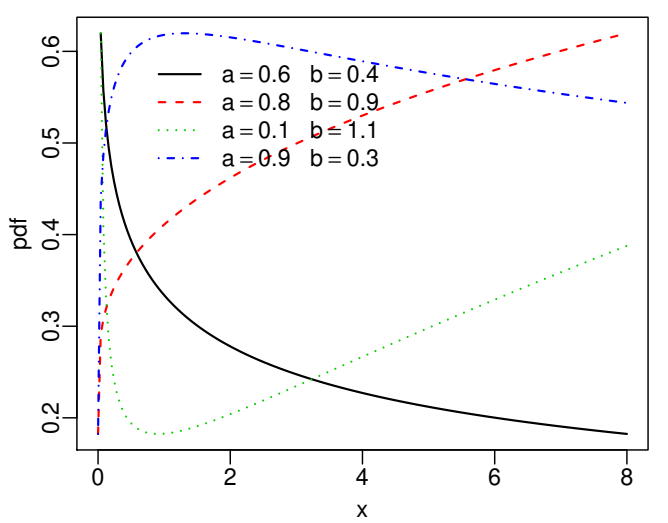

(b)

Figure 2. Special hrfs: (a) $\operatorname{SBXII}(a, b, 1.9,0.4,2.2)$ and (b) $\operatorname{SW}(a, b, 0.7,1.5)$ distributions.

\section{Linear Representation}

Given a cdf $G(z ; \eta)$ with a $q$-parameter vector $\eta$, the random variable $Z_{a} \sim \exp -G(a, \eta)$ has the exponentiated-G (exp-G) density with power parameter $a>0$, say $h(z ; a, \eta)=$ $\operatorname{ag}(z ; \boldsymbol{\eta}) G(z ; \boldsymbol{\eta})^{a-1}$, where $g(z ; \boldsymbol{\eta})=d G(z ; \boldsymbol{\eta}) / d z$. In the last 20 years, more than 35 exponentiated distributions have been published, and their structural properties are well-known. 
The power series holds

$$
\exp \left\{-\{-\log [1-G(x ; \boldsymbol{\eta})]\}^{b}\right\}=\sum_{j=0}^{\infty} \frac{(-1)^{j}}{j !}\{-\log [1-G(x ; \boldsymbol{\eta})]\}^{j b} .
$$

Plugging the last expression in Equation (2) gives

$$
\begin{aligned}
f_{\mathrm{SG}}(x ; a, b, \boldsymbol{\eta})= & \frac{b}{\Gamma(a / b)[1-G(x ; \boldsymbol{\eta})]} g(x ; \boldsymbol{\eta}) \\
& \times \sum_{j=0}^{\infty} \frac{(-1)^{j}}{j !}\{-\log [1-G(x ; \boldsymbol{\eta})]\}^{j b+a-1} .
\end{aligned}
$$

For $|z|<1$ and any real $a \neq 0$, the two expansions hold

$$
(1-z)^{a}=\sum_{m=0}^{\infty}(-1)^{m}\left(\begin{array}{c}
a \\
m
\end{array}\right) z^{m}
$$

and

$$
[-\log (1-z)]^{a}=\sum_{n=0}^{\infty} R_{n}(a) z^{n+a} .
$$

Here, $R_{0}(a)=1$ and $R_{n}(a)=a \delta_{n-1}(n+a-1)$ (for $\left.n \geq 1\right)$, and the coefficients $\delta_{n-1}(\cdot)$ are Stirling polynomials given by [35]

$$
\begin{aligned}
\delta_{n-1}(w)= & \frac{(-1)^{n-1}}{(n+1) !}\left[T_{n}^{n-1}-\frac{(w+2)}{(n+2)} T_{n}^{n-2}+\frac{(w+2)(w+3)}{(n+2)(n+3)} T_{n}^{n-3}\right. \\
& \left.-\cdots+(-1)^{n-1} \frac{(w+2)(w+3) \cdots(w+n)}{(n+2)(n+3) \cdots(2 n)} T_{n}^{0}\right],
\end{aligned}
$$

where $T_{0}^{0}=1, T_{n+1}^{0}=1 \times 3 \times \ldots \times(2 n+1), T_{n+1}^{n}=1$, and

$$
T_{n+1}^{m}=(2 n+1-m) T_{n}^{m}+(n-m+1) T_{n}^{m-1} .
$$

Thus, we can write from Equations (5) and (6)

$$
[1-G(x ; \boldsymbol{\eta})]^{-1}=\sum_{m=0}^{\infty} G(x ; \boldsymbol{\eta})^{m}
$$

and

$$
\{-\log [1-G(x ; \eta)]\}^{j b+a-1}=\sum_{n=0}^{\infty} R_{n}(j b+a-1) G(x ; \eta)^{n+j b+a-1} .
$$

Inserting these expansions in Equation (4) and after some algebra

$$
f_{\mathrm{SG}}(x ; a, b, \boldsymbol{\eta})=\sum_{j, m, n=0}^{\infty} w_{j, m, n} h(x ; m+n+j b+a, \boldsymbol{\eta}),
$$

where $h(x ;(m+n+j b+a), \boldsymbol{\eta})$ is the exp- $G(m+n+j b+a, \boldsymbol{\eta})$ density and

$$
w_{j, m, n}=w_{j, m, n}(a, b)=\frac{(-1)^{j} b R_{n}(j b+a-1)}{(m+n+j b+a) \Gamma(a / b) j !} .
$$

According to (7), the SG density function is a linear combination of exp-G densities. So, some of its mathematical properties can be easily obtained from those of the exp-G distribution. In practice, the infinity can be changed by a number such as 20 . 


\section{Mathematical Properties}

Let $W \sim \mathrm{S}(a, b, 1)$ and $Q_{G}(u ; \eta)=G^{-1}(u ; \eta)$ be the quantile function (qf) of $\mathrm{G}$. The transformed random variable $X=Q_{G}(W ; \eta)$ has density function (2), and qf

$$
Q_{\mathrm{SG}}(u ; a, b, \boldsymbol{\eta})=Q_{G}\left(1-\exp \left\{-Q^{-1}(a / b, 1-u)^{1 / b}\right\} ; \boldsymbol{\eta}\right), \quad 0<u<1,
$$

where $t=Q^{-1}(a, u)$, and $Q(a, t)=1-\gamma(a, t) / \Gamma(a)=u$. So, variates from the SG family can be simulated from (8).

Further, let $Z_{j, m, n} \sim \exp -G(m+n+j b+a, \eta)$ (for $m, n, j \geq 0$ ). Some properties of $X$ can be obtained from those of $Z_{j, m, n}$ for at least 35 parents $G$.

For example, the $p$ th ordinary moment of $X$ is obtained from (7) as

$$
\begin{aligned}
\mathbb{E}\left[X^{p}\right] & =\sum_{j, m, n=0}^{\infty} w_{j, m, n} \mathbb{E}\left[Z_{j, m, n}^{p}\right] \\
& =\sum_{j, m, n=0}^{\infty}(m+n+j b+a) w_{j, m, n} \int_{0}^{1} Q_{\mathrm{G}}(u ; \eta)^{p} u^{m+n+j b+a-1} d u .
\end{aligned}
$$

The moments of some generated models can be much simpler and practically hasslefree. For example, for the SW distribution, the $p$ th moment is

$$
\mathbb{E}\left[X^{p}\right]=\frac{\beta^{\alpha(a-1)-p} \Gamma\left(\frac{p+\alpha}{b \alpha}\right)}{\Gamma\left(\frac{a}{b}\right)} .
$$

Further, the generating function (gf) of $X$ comes from (7) as

$$
\begin{aligned}
M_{X}(t) & =\sum_{j, m, n=0}^{\infty} w_{j, m, n} M_{j, m, n}(t) \\
& =\sum_{j, m, n=0}^{\infty}(m+n+j b+a) w_{j, m, n} \int_{0}^{1} \mathrm{e}^{t Q_{\mathrm{G}}(u ; \eta)} u^{m+n+j b+a-1} d u
\end{aligned}
$$

where $M_{j, m, n}(t)$ is the gf of $Z_{j, m, n}$.

Plots of the skewness and kurtosis of $X$ using $\mathrm{R}$ [36] are reported in Figure 3. These measures can be increasing, decreasing, decreasing-increasing, and increasing-decreasing depending on the parameter values.

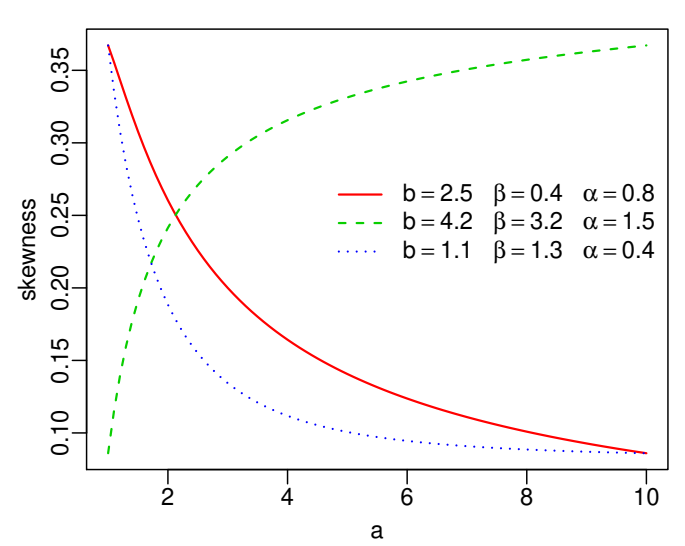

(a)

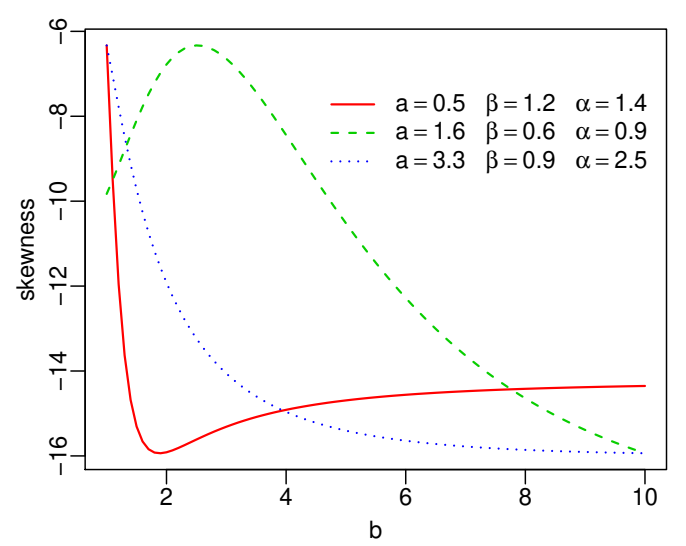

(b)

Figure 3. Cont. 


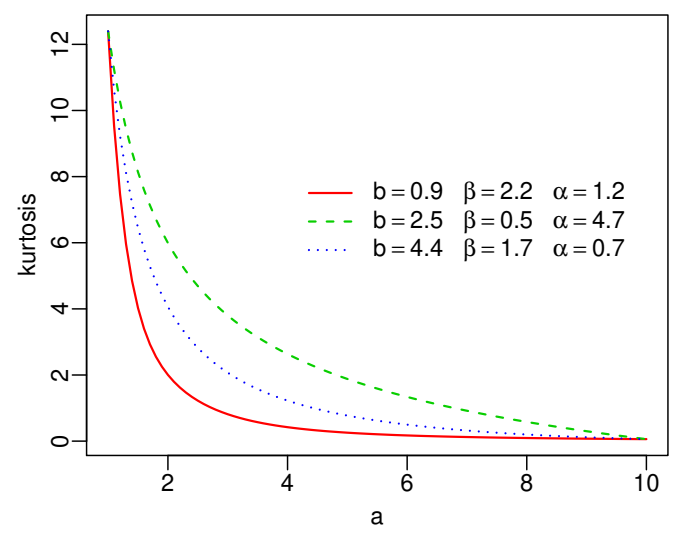

(c)

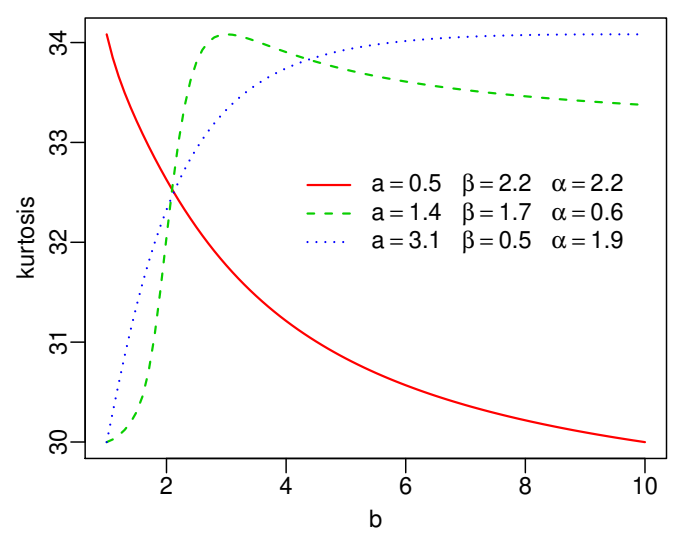

(d)

Figure 3. Skewness and kurtosis of the $\operatorname{SW}(a, b, \beta, \alpha)$ distribution(a-d).

\section{Estimation}

Let $X_{i}, \cdots, X_{n} \sim \mathrm{SG}(a, b, \eta)$ be independent and identically distributed (iid) random variables from (2). The $\log$-likelihood $\ell(a, b, \eta)$ for the parameters from the observed values $x_{i}, \cdots, x_{n}$ has the form

$$
\begin{aligned}
\ell(a, b, \boldsymbol{\eta})= & n \log b+\sum_{i=1}^{n} \log g\left(x_{i} ; \boldsymbol{\eta}\right)+(a-1) \sum_{i=1}^{n} \log \left\{-\log \left[1-G\left(x_{i} ; \boldsymbol{\eta}\right)\right]\right\} \\
& -n \log \Gamma(a / b)-\sum_{i=1}^{n}\left\{-\log \left[1-G\left(x_{i} ; \boldsymbol{\eta}\right)\right]\right\}^{b}-\sum_{i=1}^{n} \log \left[1-G\left(x_{i} ; \boldsymbol{\eta}\right)\right] .
\end{aligned}
$$

The maximum likelihood estimates (MLEs) can be found by maximizing $\ell(a, b, \eta)$ numerically with respect to the parameters. There are several routines available for the maximization in SAS (PROC NLMIXED), R (optim function), and Ox (sub-routine MaxBFGS).

\section{Simulation Study}

Consider the $\operatorname{SC}(a, b, \lambda, \beta)$ distribution with sample sizes $n=50,100,150,200$, and 300. We carry out Monte Carlo simulations with 5000 replications to examine the estimation accuracy. The observations are generated from Equation (8), where $Q_{\mathrm{G}}(\cdot)$ is the Chen qf. The true parameters are: $a=0.5, b=0.9, \lambda=0.4$ and $\beta=1.6$. The simulations were done using the matrix programming language $0 x$ (version 8.02) [37] with the MaxBFGS sub-routine.

The average estimates (AEs), mean square errors (MSEs), and coverage rates of the 95\% confidence intervals (CIs) are reported in Table 2. The AEs tend to the true parameters and the MSEs decrease to small values when $n$ increases, thus showing that the estimates are consistent. The simulated CIs are a little greater than $95 \%$. 
Table 2. Simulation results from the SC distribution.

\begin{tabular}{|c|c|c|c|c|c|c|}
\hline$n$ & Parameter & $\mathrm{AE}$ & MSE & CI (95\%) & Lower (95\%) & Upp (95\%) \\
\hline \multirow{4}{*}{50} & $a$ & 0.66985 & 0.17353 & 97.10 & -0.71499 & 2.05469 \\
\hline & $b$ & 1.68281 & 2.40263 & 99.84 & -4.35142 & 7.71705 \\
\hline & $\lambda$ & 0.53627 & 0.24883 & 97.22 & -1.35293 & 2.42547 \\
\hline & $\beta$ & 1.54150 & 0.57595 & 97.50 & -1.30041 & 4.38342 \\
\hline \multirow{4}{*}{100} & $a$ & 0.60645 & 0.08474 & 97.04 & -0.26556 & 1.47846 \\
\hline & $b$ & 1.38420 & 1.34967 & 99.24 & -2.39347 & 5.16186 \\
\hline & $\lambda$ & 0.54260 & 0.19692 & 97.86 & -0.79272 & 1.87793 \\
\hline & $\beta$ & 1.56706 & 0.38844 & 97.84 & -0.52915 & 3.66326 \\
\hline \multirow{4}{*}{150} & $a$ & 0.57948 & 0.05794 & 96.72 & -0.09699 & 1.25595 \\
\hline & $b$ & 1.25828 & 0.96073 & 97.98 & -1.63989 & 4.15645 \\
\hline & $\lambda$ & 0.53119 & 0.16704 & 97.36 & -0.50848 & 1.57086 \\
\hline & $\beta$ & 1.58631 & 0.31278 & 97.98 & -0.16239 & 3.33502 \\
\hline \multirow{4}{*}{200} & $a$ & 0.56642 & 0.04409 & 96.56 & -0.00289 & 1.13573 \\
\hline & $b$ & 1.18037 & 0.73833 & 97.20 & -1.21682 & 3.57755 \\
\hline & $\lambda$ & 0.52359 & 0.12400 & 97.66 & -0.32081 & 1.36799 \\
\hline & $\beta$ & 1.59431 & 0.27028 & 98.40 & 0.06641 & 3.12220 \\
\hline \multirow{4}{*}{300} & $a$ & 0.54599 & 0.02824 & 96.44 & 0.11532 & 0.97666 \\
\hline & $b$ & 1.09099 & 0.47169 & 95.08 & -0.70170 & 2.88367 \\
\hline & $\lambda$ & 0.49700 & 0.08405 & 97.52 & -0.10430 & 1.09830 \\
\hline & $\beta$ & 1.60415 & 0.20480 & 98.34 & 0.34577 & 2.86254 \\
\hline
\end{tabular}

\section{Regression}

Consider the random variables $X$ with pdf (3) and $Y=\log X$. Setting $s=\mathrm{e}^{\mu}$ and $c=\sigma^{-1}$, the density of $Y$ (for $y \in \mathbb{R}$ ) can be expressed as

$$
\begin{aligned}
f_{\mathrm{LSBXII}}(y ; a, b, \mu, d, \sigma)= & \frac{b d^{a}}{\sigma \Gamma(a / b)} \mathrm{e}^{\frac{y-\mu}{\sigma}}\left[1+\mathrm{e}^{\frac{y-\mu}{\sigma}}\right]^{-1}\left\{\log \left[1+\mathrm{e}^{\frac{y-\mu}{\sigma}}\right]\right\}^{a-1} \\
& \times \exp \left\{-\left\{d \log \left[1+\mathrm{e}^{\frac{y-\mu}{\sigma}}\right]\right\}^{b}\right\},
\end{aligned}
$$

where $a, b, d, \sigma>0$ and $\mu \in \mathbb{R}$. Equation (9) has the location-scale form, where $\mu$ is a location and $\sigma$ is a scale. The random variable $Y$ has the log-Stacy-Burr XII (LSBXII) distribution. So, if $X \sim \operatorname{SBXII}(a, b, s, d, c)$, then $Y=\log X \sim \operatorname{LSBXII}(a, b, \mu, d, \sigma)$.

Equation (9) has some special cases. For $b=1$ and $b=d=1$, we have the log-gammaBurr XII (new) and log-gamma-log-logistic (new), respectively. For $a=b=1$, it is equal to the log-Burr XII (LBXII) density [38]. Finally, the well-know logistic density follows when $a=b=d=1$.

The survival function corresponding to (9) is

$$
S_{\text {LSBXII }}(y ; a, b, \mu, d, \sigma)=1-\frac{\gamma\left((a / b),\left\{d \log \left[1+\mathrm{e}^{\frac{y-\mu}{\sigma}}\right]\right\}^{b}\right)}{\Gamma(a / b)} .
$$

The density of $Z=(Y-\mu) / \sigma$ (for $z \in \mathbb{R}$ ) has the form

$$
\begin{aligned}
f_{\text {LSBXII }}(z ; a, b, d)= & \frac{b d^{a}}{\Gamma(a / b)} \mathrm{e}^{z}\left[1+\mathrm{e}^{z}\right]^{-1}\left\{\log \left[1+\mathrm{e}^{z}\right]\right\}^{a-1} \\
& \times \exp \left\{-\left\{d \log \left[1+\mathrm{e}^{z}\right]\right\}^{b}\right\} .
\end{aligned}
$$

Equation (10) refers to the standard LSBXII density.

The individuals have different characteristics that make them not identically distributed. For example, in survival analysis, it is common for the failure time to depend on explanatory variables such as fat concentration, blood pressure, glucose level, and sex, among others. 
Let $\mathrm{x}_{i}=\left(x_{i 1}, \cdots, x_{i k}\right)^{\top}$ be the explanatory vector associated with the $i$ th response variable $y_{i}$ (for $i=1, \ldots, n$ ), and $\beta=\left(\beta_{1}, \cdots, \beta_{k}\right)^{\top}$ be the parameter vector. We construct a regression based on the LSBXII distribution

$$
y_{i}=\mathbf{x}_{i}^{\top} \boldsymbol{\beta}+\sigma z_{i}, \quad i=1, \ldots, n,
$$

where $\mu_{i}=\mathbf{X}_{i}^{\top} \boldsymbol{\beta}$, and $z_{i}$ is the random error having density function (10).

The density and survival functions of $Y_{i}$ are

$$
\begin{aligned}
f_{\mathrm{LSBXII}}\left(y_{i} ; a, b, d, \sigma, \boldsymbol{\beta}^{\top}\right)= & \frac{b d^{a}}{\sigma \Gamma(a / b)} \mathrm{e}^{z_{i}}\left[1+\mathrm{e}^{z_{i}}\right]^{-1}\left\{\log \left[1+\mathrm{e}^{z_{i}}\right]\right\}^{a-1} \\
& \times \exp \left\{-\left\{d \log \left[1+\mathrm{e}^{z_{i}}\right]\right\}^{b}\right\}
\end{aligned}
$$

and

$$
S_{\mathrm{LSBXII}}\left(y_{i} ; a, b, d, \sigma, \boldsymbol{\beta}^{\top}\right)=1-\frac{\gamma\left((a / b),\left\{d \log \left[1+\mathrm{e}^{z_{i}}\right]\right\}^{b}\right)}{\Gamma(a / b)},
$$

where $z_{i}=\left(y_{i}-\mathbf{x}_{i}^{\top} \boldsymbol{\beta}\right) / \sigma$. The sets of individuals for which $y_{i}$ is the log-lifetime or logcensoring are denoted by $F$ and $C$ with $r$ and $n-r$ observations, respectively. Thus, the $\log$-likelihood for $\boldsymbol{\theta}=\left(a, b, d, \sigma, \boldsymbol{\beta}^{\top}\right)^{\top}$ from model (11) has the form

$$
\begin{aligned}
\ell(\boldsymbol{\theta})= & r \log \left(\frac{b d^{a}}{\sigma \Gamma(a / b)}\right)+\sum_{i \in F} z_{i}-\sum_{i \in F} \log \left[1+\mathrm{e}^{z_{i}}\right] \\
& +(a-1) \sum_{i \in F} \log \left\{\log \left[1+\mathrm{e}^{z_{i}}\right]\right\}-\sum_{i \in F}\left\{d \log \left[1+\mathrm{e}^{z_{i}}\right]\right\}^{b} \\
& +\sum_{i \in C} \log \left\{1-\frac{\gamma\left((a / b),\left\{d \log \left[1+\mathrm{e}^{z_{i}}\right]\right\}^{b}\right)}{\Gamma(a / b)}\right\} .
\end{aligned}
$$

For $r=n, y_{i} \in F(\forall i)$, the log-likelihood (12) reduces to the usual log-likelihood. The MLE $\hat{\boldsymbol{\theta}}$ can be found by maximizing (12) numerically using the optim function of $\mathrm{R}$ [36].

We assume that the asymptotic likelihood theory holds, i.e., $(\hat{\boldsymbol{\theta}}-\boldsymbol{\theta}) \stackrel{a}{\sim} \mathcal{N}_{k+4}\left(\mathbf{0}, \mathbf{J}^{-1}(\boldsymbol{\theta})\right)$, where $\stackrel{a}{\sim}$ denotes asymptotic distribution and $\mathbf{J}(\boldsymbol{\theta})$ is the observed information matrix for the model parameters.

\section{Applications}

We prove the potentiality of the proposed models by means of three applications, as well as the utility of the proposed models by means of three applications (Appendix A). We apply the SBXII distribution to two uncensored data in the first two, and we fit the LSBXII regression to censored data in the third one.

\subsection{Uncensored Data}

The uncensored data sets are:

1. The first data set consists of the sum of skin folds in 202 athletes collected at the Australian Institute of Sports (skin folds data). These data were also analyzed by [39];

2. The second data set $(n=40)$, discussed by [40] and [22], refers to the time-to-failure $\left(10^{3} \mathrm{~h}\right)$ of a particular type of engine (turbocharger data).

We fit five distributions: SBXII (3), gamma-Burr XII [31], beta-Burr XII (BBXII) [41], Kumaraswamy-Burr XII (KBXII) [42], and Weibull-Burr XII [43] to both data sets.

The BBXII and KBXII densities are (for $x>0$ )

$$
\begin{aligned}
f_{\mathrm{BBXII}}(x ; a, b, s, d, c)= & \frac{c d}{s^{c} B(a, b)} x^{c-1}\left[1+(x / s)^{c}\right]^{-(d b+1)} \\
& \times\left\{1-\left[1+(x / s)^{c}\right]^{-d}\right\}^{a-1}
\end{aligned}
$$


and

$$
\begin{aligned}
f_{\mathrm{KBXII}}(x ; a, b, s, d, c)= & a b c d s^{-c} x^{c-1}\left[1+(x / s)^{c}\right]^{-(d+1)}\left\{1-\left[1+(x / s)^{c}\right]^{-d}\right\}^{a-1} \\
& \times\left\{1-\left\{1-\left[1+(x / s)^{c}\right]^{-d}\right\}^{a}\right\}^{b-1},
\end{aligned}
$$

respectively, where all parameters are positive.

The Weibull-Burr XII (WBXII) density introduced by [43] (taking the scale parameter $s=1)$ is (for $x>0$ )

$$
\begin{aligned}
f_{\mathrm{WBXII}}(x ; a, b, d, c)= & a b c d x^{c-1}\left(1+x^{c}\right)^{b d-1}\left[1-\left(1+x^{c}\right)^{-d}\right]^{b-1} \\
& \times \exp \left\{-a\left[\left(1+x^{c}\right)^{d}-1\right]^{b}\right\},
\end{aligned}
$$

where all parameters are positive.

The MLEs for all models are calculated using the optim function (with BFGS method) available in $\mathrm{R}$ [36]. We adopt the Cramér-von Mises $\left(W^{*}\right)$ and Anderson-Darling $\left(A^{*}\right)$ measures [44] for model comparisions. The MLEs and their standard errors (SEs) in parentheses and the information criteria are reported in Tables 3 and 4 for both data sets, where the statistics $W^{*}$ and $A^{*}$ reveal that the SBXII distribution provides the best fit

\begin{tabular}{|c|c|c|c|c|c|}
\hline Distribution & $a$ & $b$ & $s$ & $d$ & $c$ \\
\hline \multirow{2}{*}{ BXII } & - & - & 47.3209 & 0.4885 & 5.2992 \\
\hline & - & - & (5.8102) & (0.1909) & (1.1667) \\
\hline \multirow{2}{*}{ GBXII } & 6.7710 & - & 19.1049 & 0.4019 & 14.2138 \\
\hline & $(4.3046)$ & - & $(6.3462)$ & $(0.3117)$ & (9.9266) \\
\hline \multirow{2}{*}{ SBXII } & 1.1357 & 4.4497 & 29.7613 & 0.0307 & 22.6525 \\
\hline & $(0.1854)$ & (1.1481) & (1.3755) & $(0.0090)$ & (6.3063) \\
\hline \multirow{2}{*}{ BBXII } & 8.7445 & 9.0397 & 16.8470 & 0.0671 & 8.0123 \\
\hline & (6.7799) & $(10.2228)$ & $(7.4968)$ & $(0.0684)$ & $(6.9791)$ \\
\hline \multirow{2}{*}{ KBXII } & 2.5656 & 21.4299 & 24.8132 & 0.0181 & 18.9969 \\
\hline & $(0.6304)$ & $(9.2078)$ & $(2.9297)$ & $(0.0054)$ & $(5.2688)$ \\
\hline \multirow{2}{*}{ WBXII } & 0.4688 & 6.9807 & - & 0.1133 & 1.5193 \\
\hline & $(0.2857)$ & $(0.3949)$ & - & $(0.0197)$ & $(0.2571)$ \\
\hline Distribution & $W^{*}$ & $A^{*}$ & & & \\
\hline BXII & 0.2803 & 1.8868 & & & \\
\hline GBXII & 0.1564 & 1.1153 & & & \\
\hline SBXII & 0.0670 & 0.4116 & & & \\
\hline BBXII & 0.1602 & 1.1205 & & & \\
\hline KBXII & 0.1325 & 0.9377 & & & \\
\hline WBXII & 0.5443 & 3.1913 & & & \\
\hline
\end{tabular}
followed by the KBXII distribution in the first case, and by the GBXII distribution in the second case.

Table 3. Results from the fitted models to skin folds data.

The likelihood ratio (LR) test can be sed for the sub-models GBXII and BXII of the SBXII distribution for $a=1$ and $a=b=1$, respectively. Table 5 reports the LR tests for both datasets. Except for SBXII vs. GBXII in the turbocharger data, which is at the $10 \%$ significance threshold, all LR tests are highly significant. Then, the SBXII model fits the data better than its sub-models.

Figures 4 and 5 display the histogram and Kaplan-Meier empirical cdf in conjunction with the best estimated pdfs and cdfs for both datasets. The superiority of the SBXII model is supported by the statistics $W^{*}$ and $A^{*}$. 
Table 4. Results from the fitted models to the turbocharger data.

\begin{tabular}{cccccc}
\hline Distribution & $\boldsymbol{a}$ & $\boldsymbol{b}$ & $\boldsymbol{s}$ & $\boldsymbol{d}$ & $\boldsymbol{c}$ \\
\hline \multirow{2}{*}{ BXII } & - & - & 17.4122 & 36.2491 & 3.8786 \\
& - & - & $(7.1825)$ & $(52.4338)$ & $(0.5282)$ \\
GBXII & 0.1577 & - & 10.0683 & 8.9154 & 16.3307 \\
& $(0.0267)$ & - & $(0.0435)$ & $(3.9008)$ & $(0.0435)$ \\
SBXII & 0.1559 & 25.0319 & 9.3438 & 2.1176 & 15.3057 \\
& $(0.0249)$ & $(59.5089)$ & $(0.2099)$ & $(0.6168)$ & $(0.2090)$ \\
BBXII & 0.1676 & 9.0200 & 10.7368 & 2.5707 & 15.5021 \\
& $(0.0284)$ & $(3.8937)$ & $(0.0555)$ & $(0.0309)$ & $(0.0622)$ \\
KBXII & 0.3557 & 14.1922 & 18.0505 & 10.1027 & 10.3163 \\
& $(0.0534)$ & $(9.6999)$ & $(1.0707)$ & $(15.5092)$ & $(0.5361)$ \\
WBXII & 0.0099 & 6.5239 & - & 0.7123 & 0.6825 \\
& $(0.0109)$ & $(3.3203)$ & - & $(0.1775)$ & $(0.4227)$ \\
\hline Distribution & $W^{*}$ & $A^{*}$ & & & \\
\hline BXII & 0.0796 & 0.5913 & & & \\
GBXII & 0.0153 & 0.1220 & & & \\
SBXII & 0.0114 & 0.0866 & & & \\
BBXII & 0.0154 & 0.1222 & & & \\
KBXII & 0.0693 & 0.5228 & & & \\
WBXII & 0.0830 & 0.6136 & & &
\end{tabular}

Table 5. LR tests for skin folds and turbocharger data.

\begin{tabular}{cccc}
\hline Model & \multicolumn{1}{c}{ Hypotheses } & LR & $p$-Value \\
\hline GBXII vs. SBXII & $\begin{array}{c}\mathcal{H}_{0}: b=1 \text { vs. } \mathcal{H}_{1}: \mathcal{H}_{0} \\
\text { is false } \\
\text { BXII vs. SBXII }\end{array}$ & $\begin{array}{c}\mathcal{H}_{0}: a=1 \text { vs. } \mathcal{H}_{1}: \\
\mathcal{H}_{0} \text { is false }\end{array}$ & 0.0001 \\
\hline \multicolumn{1}{c}{ turbocharger data } & $<3.7721$ & $<0.0001$ \\
\hline GBXII vs. SBXII & $\begin{array}{c}\mathcal{H}_{0}: b=1 \text { vs. } \mathcal{H}_{1}: \mathcal{H}_{0} \\
\text { is false } \\
\text { BXII vs. SBXII }\end{array}$ & $\begin{array}{c}\mathcal{H}_{0}: a=1 \text { vs. } \mathcal{H}_{1}: \\
\mathcal{H}_{0} \text { is false }\end{array}$ & 0.1056 \\
\hline
\end{tabular}

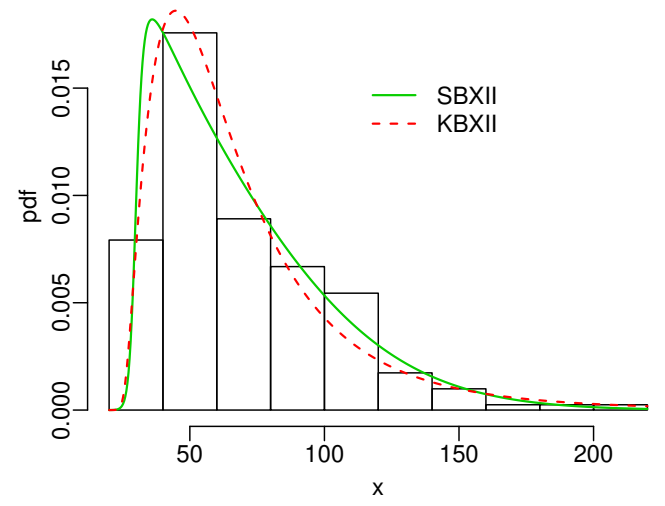

(a)

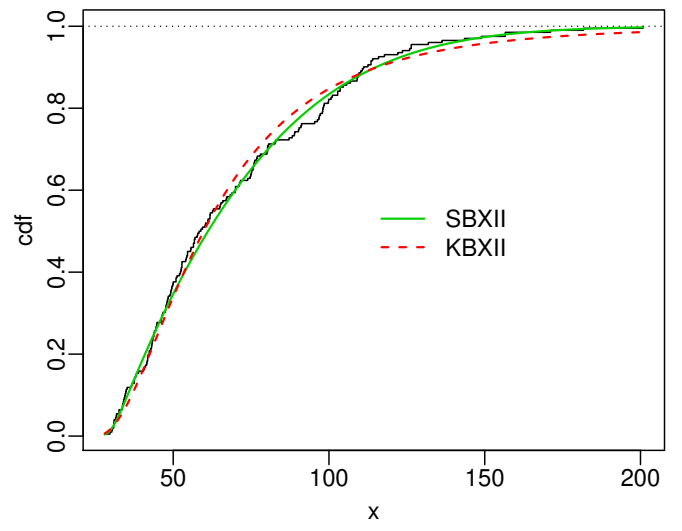

(b)

Figure 4. Estimated pdfs (a) and estimated cdfs (b) for skin folds data. 


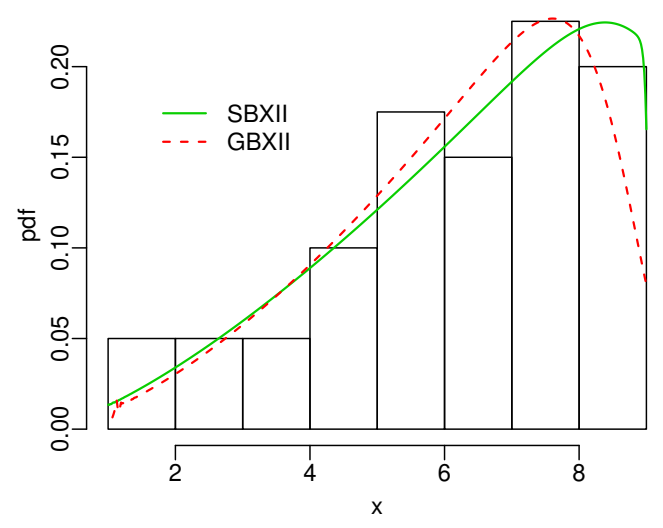

(a)

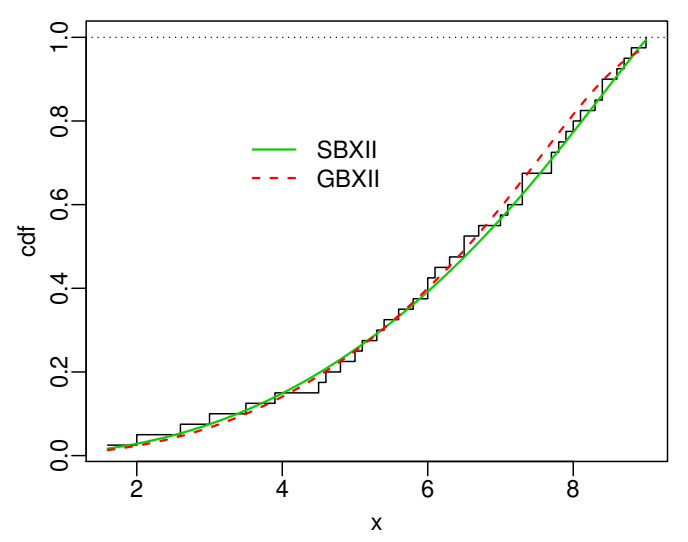

(b)

Figure 5. Estimated pdfs (a) and estimated cdfs (b) for turbocharger data.

Figures 6 and 7 display plots of the profile log-likelihood function versus some parameter values (the MLEs of the other parameters fixed) for the skin folds and turbocharger data, respectively. We can find the approximate intervals that maximize the profile loglikelihood function for each parameter. In Figure 6a, the log-likelihood is maximized for values of $a$ close to one. Similarly, it takes maximum values for $0<b<10,15<s<50$, $0.0014<d<0.05$, and $0<c<40$ according to Figure $6 \mathrm{~b}-\mathrm{e}$, respectively. The interpretation from Figure 7 is analogous. Nevertheless, there is evidence of a monotone log-likelihood in Figure $7 \mathrm{~b}$ since this function does not have a maximum in the range taken for $b$.

(a)

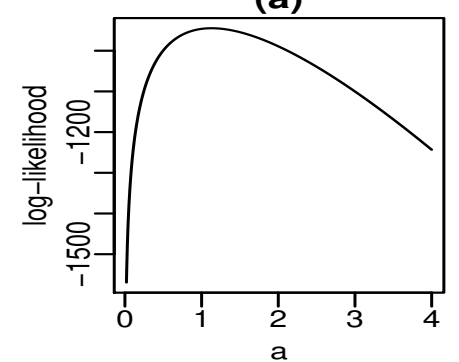

(d)

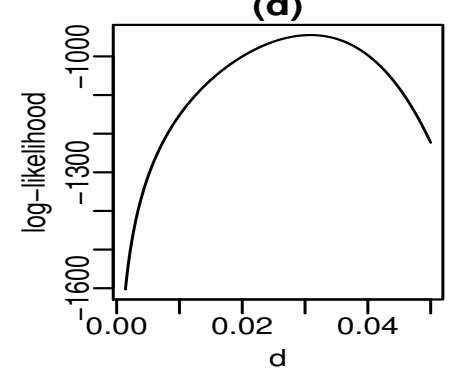

(b)

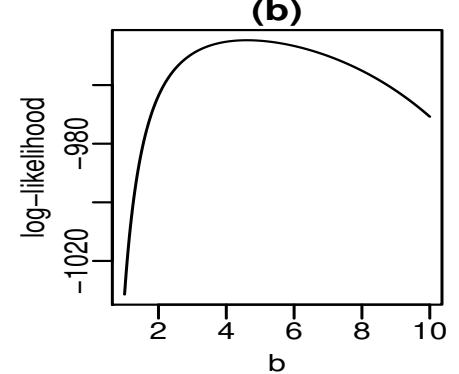

(e)

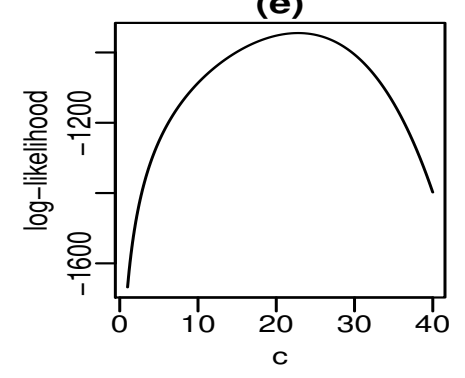

(c)

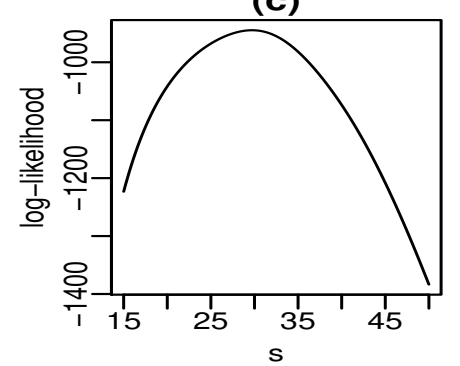

Figure 6. Profile log-likelihood functions for skin folds data (a-e). 
(a)

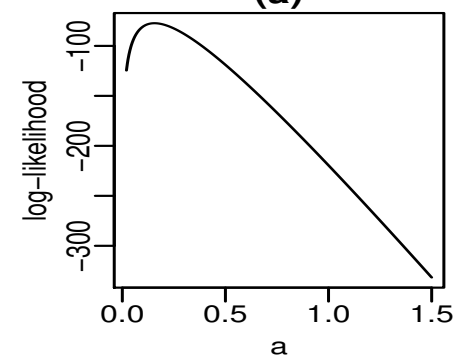

(d)

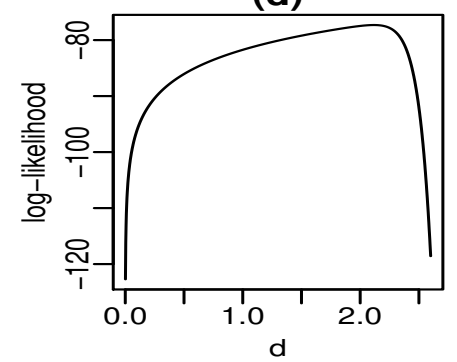

(b)

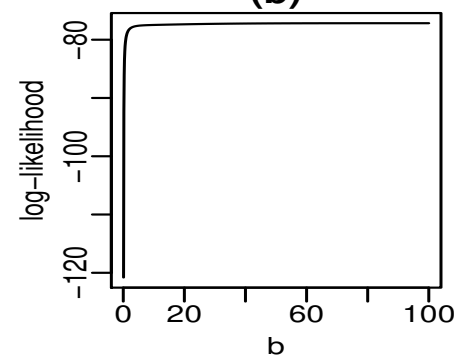

(e)

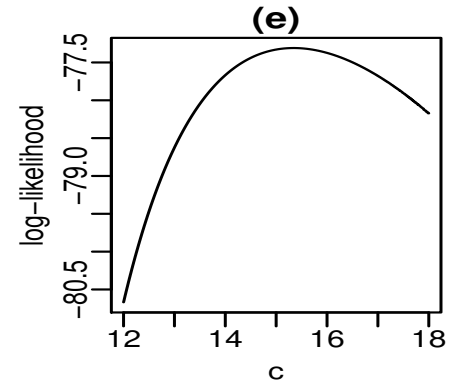

(c)

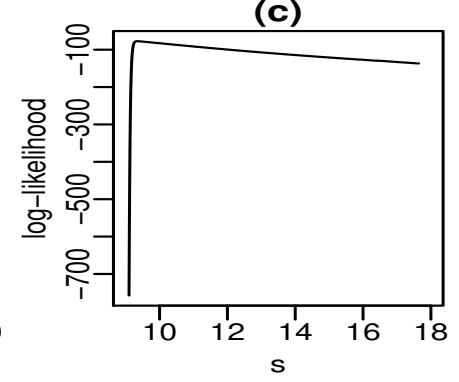

Figure 7. Profile log-likelihood functions for turbocharger data (a-e).

\subsection{Regression for Censored Data}

We apply the LSBXII regression addressed in Section 7 to the recurrence times (in years) of 417 patients with melanoma cancer under the effect of a high dose of a drug (interferon alfa-2b) [45]. The study was conducted from 1991 to 1995, and the patients were followed up until 1998 under right censoring ( $0=$ censoring and $1=$ observed lifetime). The percentage of censoring is $55.64 \%$. The explanatory variable $x_{i 1}$ (nodule category) denotes the number of lymph nodes involved in the disease $(0,1,2-3$, and $\geq 4)$. The proposed regression is

$$
y_{i}=\beta_{0}+\beta_{1} x_{i 1}+\sigma z_{i}, \quad i=1, \ldots, 417,
$$

where $z_{i}$ has density (10). Table 6 gives the MLEs, their SEs in parentheses, and $p$-values in brackets for the LSBXII regression and two sub-models fitted to these data. The estimates are statistically significant at $1 \%$ for the three models, thus showing that $x_{1}$ affects the lifetime. The negative sign of $\beta_{1}$ indicates that the higher the degree of the nodule, the shorter the failure time.

Table 6. MLEs, SEs, and $p$-values for three regression.

\begin{tabular}{ccccccc}
\hline Model & $\boldsymbol{a}$ & $\boldsymbol{b}$ & $\boldsymbol{d}$ & $\boldsymbol{\sigma}$ & $\boldsymbol{\beta}_{\mathbf{0}}$ & $\boldsymbol{\beta}_{\mathbf{1}}$ \\
\hline \multirow{3}{*}{ LSBXII } & 0.5636 & 0.1939 & 5.6590 & 0.1807 & 1.9576 & -0.2568 \\
& $(0.1664)$ & $(0.0463)$ & $(15.4211)$ & $(0.0289)$ & $(0.2748)$ & $(0.0580)$ \\
& {$[0.0007]$} & {$[0.0000]$} & {$[0.7136]$} & {$[0.0000]$} & {$[0.0000]$} & {$[0.0000]$} \\
\hline \multirow{3}{*}{ LBXII } & - & - & 0.0159 & 0.0999 & 0.8932 & -0.2148 \\
& - & - & $(0.0058)$ & $(0.0342)$ & $(0.1919)$ & $(0.0690)$ \\
& - & - & {$[0.0058]$} & {$[0.0035]$} & {$[0.0000]$} & {$[0.0018]$} \\
\hline \multirow{2}{*}{ Logistic } & - & - & - & 1.8247 & 6.5851 & -0.8718 \\
& - & - & - & $(0.1129)$ & $(0.4623)$ & $(0.1630)$ \\
& - & - & - & {$[0.0000]$} & {$[0.0000]$} & {$[0.0000]$} \\
\hline
\end{tabular}

Table 7 gives the classical statistics CAIC, AIC, BIC, and HQIC for three regressions, which reveal that the LSBXII regression is the best model for these data. 
Table 7. Adequacy measures for three regressions.

\begin{tabular}{ccccc}
\hline Model & CAIC & AIC & BIC & HQIC \\
\hline LSBXII & 1055.9662 & 1055.7613 & 1079.9598 & 1065.3284 \\
LBXII & 1079.4012 & 1079.3042 & 1095.4365 & 1085.6822 \\
Logistic & 1243.0194 & 1242.9613 & 1255.0606 & 1247.7449 \\
\hline
\end{tabular}

The LR statistics comparing the LSBXII regression with two sub-models in Table 8 also support that the LSBXII model is the best model among the three.

Table 8. LR tests for three regressions.

\begin{tabular}{|c|c|c|c|}
\hline Model & Hyphotheses & LR & $p$-Value \\
\hline LBXII vs. LSBXII & $\begin{array}{c}\mathcal{H}_{0}: a=b=1 \text { vs. } \mathcal{H}_{1}: \\
\mathcal{H}_{0} \text { is false }\end{array}$ & 13.7714 & $<0.0001$ \\
\hline Logistic vs. LSBXII & $\begin{array}{c}\mathcal{H}_{0}: a=b=d=1 \mathrm{vs} \\
\mathcal{H}_{1}: \mathcal{H}_{0} \text { is false }\end{array}$ & 96.6000 & $<0.0001$ \\
\hline
\end{tabular}

\section{Conclusions}

We defined a new Stacy-G class of distributions, which extends the gamma-G family [30], and proved its flexibility. Some of its mathematical properties were presented. A simulation study showed the consistency of the maximum likelihood estimators. We constructed a new log-Stacy-Burr XII regression for censored data. Three applications to real data using the Burr XII baseline revealed the utility of the proposed models when compared to other models.

Author Contributions: Conceptualization, L.D.R.R., M.d.C.S.L. and G.M.C.; methodology, L.D.R.R., M.d.C.S.L. and G.M.C.; software, L.D.R.R. and M.d.C.S.L.; validation, G.M.C.; formal analysis, L.D.R.R. and M.d.C.S.L.; investigation, L.D.R.R. and M.d.C.S.L.; data curation, L.D.R.R.; writingoriginal draft preparation, L.D.R.R. and M.d.C.S.L.; writing-review and editing, G.M.C.; visualization, L.D.R.R.; supervision, M.d.C.S.L. and G.M.C.; project administration, M.d.C.S.L. and G.M.C. All authors have read and agreed to the published version of the manuscript.

Funding: This research received no external funding.

Institutional Review Board Statement: Not applicable.

Informed Consent Statement: Not applicable.

Data Availability Statement: The applications data sets are found in the references cited.

Acknowledgments: The authors would like to thank the Fundação de Amparo à Ciência e Tecnologia do Estado de Pernambuco (FACEPE) for funding the doctoral scholarship.

Conflicts of Interest: The authors declare no conflict of interest.

\section{Abbreviations}

The following abbreviations are used in this manuscript:

$\begin{array}{ll}\text { AIC } & \text { Akaike Information Criterion } \\ \text { BIC } & \text { Bayesian Information Criterion } \\ \text { CAIC } & \text { Consistent Akaike Information Criterion } \\ \text { exp-G } & \text { Exponentiated-G } \\ \text { HQIC } & \text { Hannan-Quinn Information Criterion } \\ \text { SG } & \text { Stacy-G }\end{array}$

\section{Appendix A. Codes}

Appendix A.1. Figures Codes 


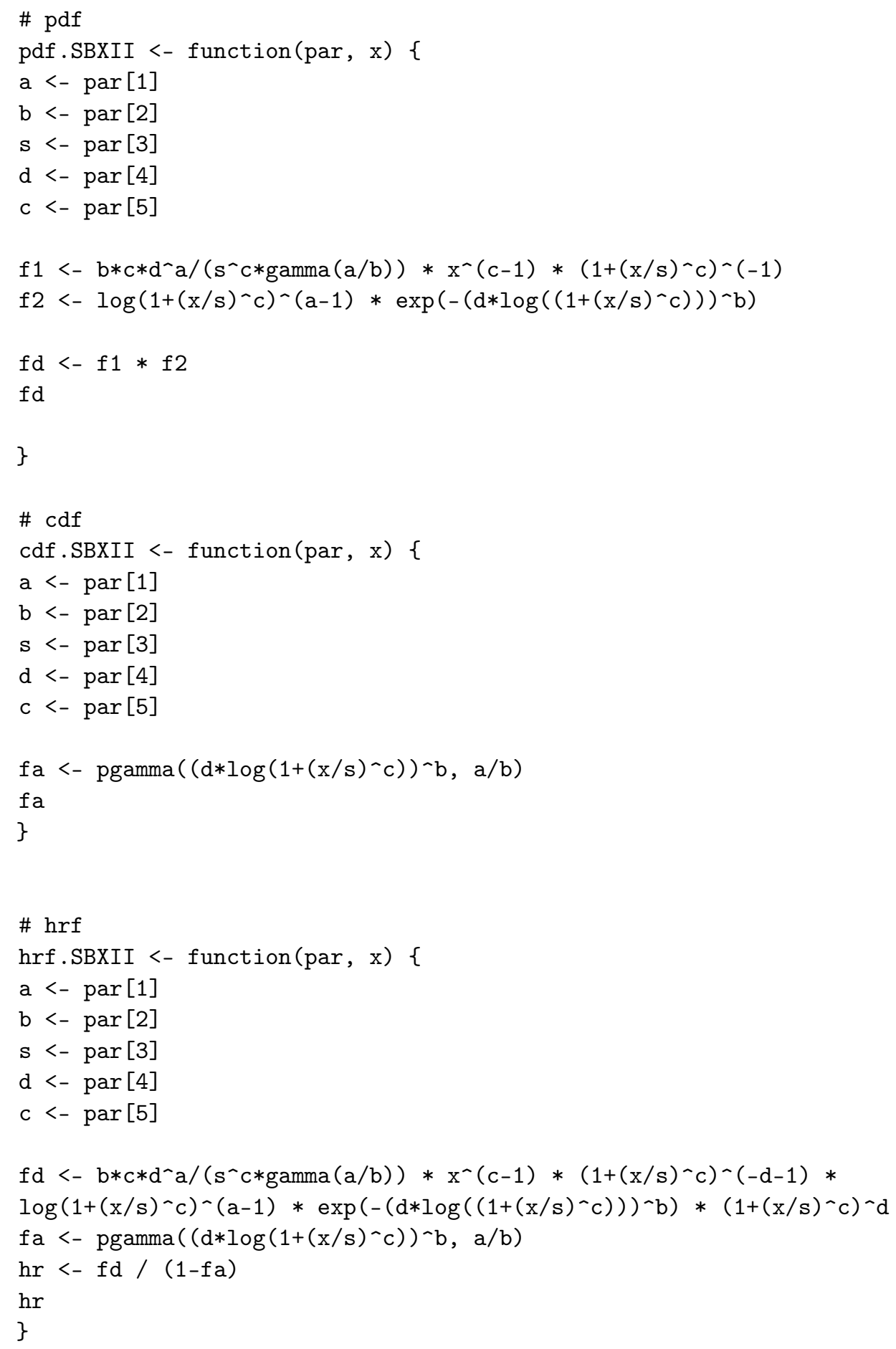




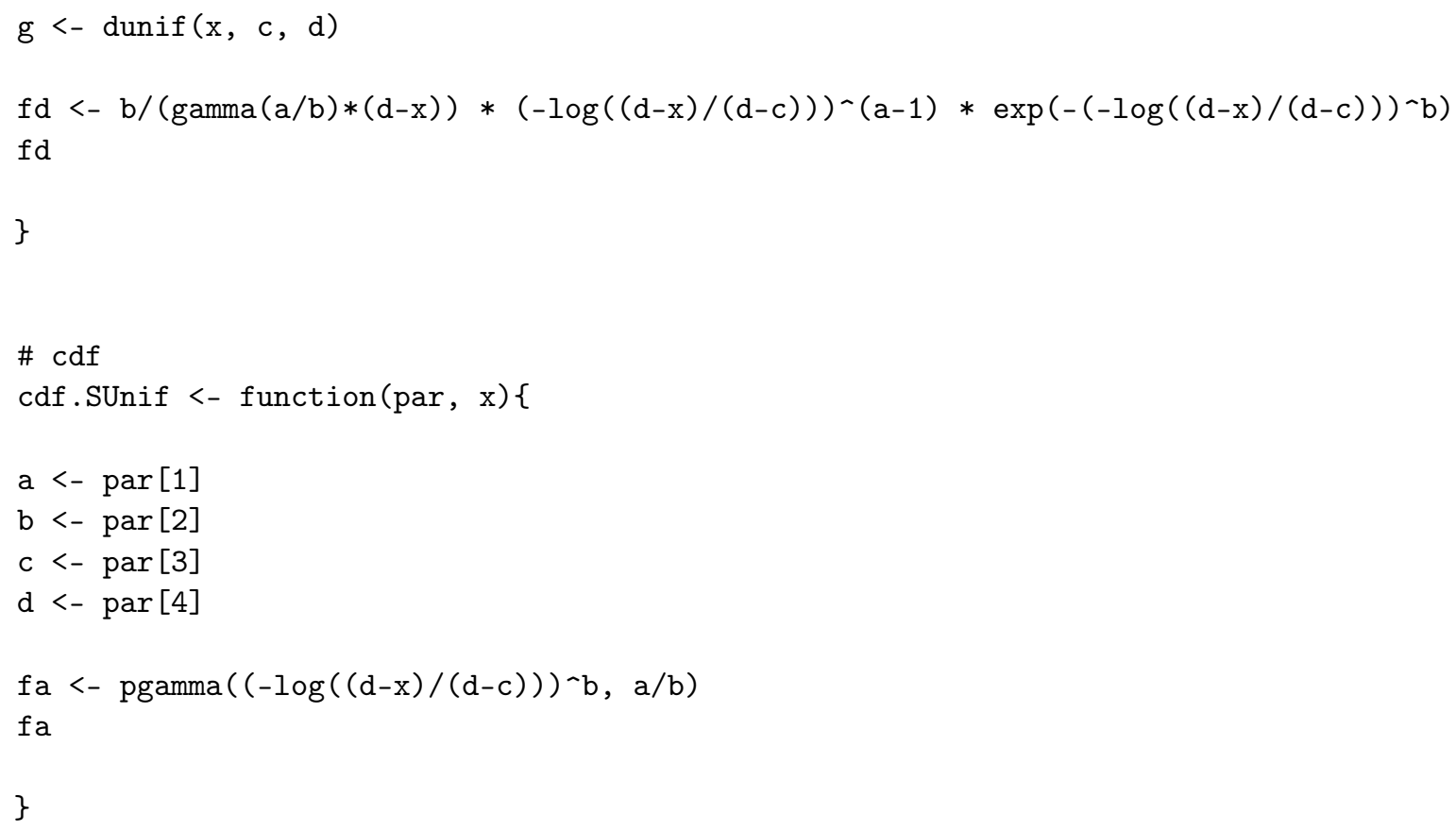




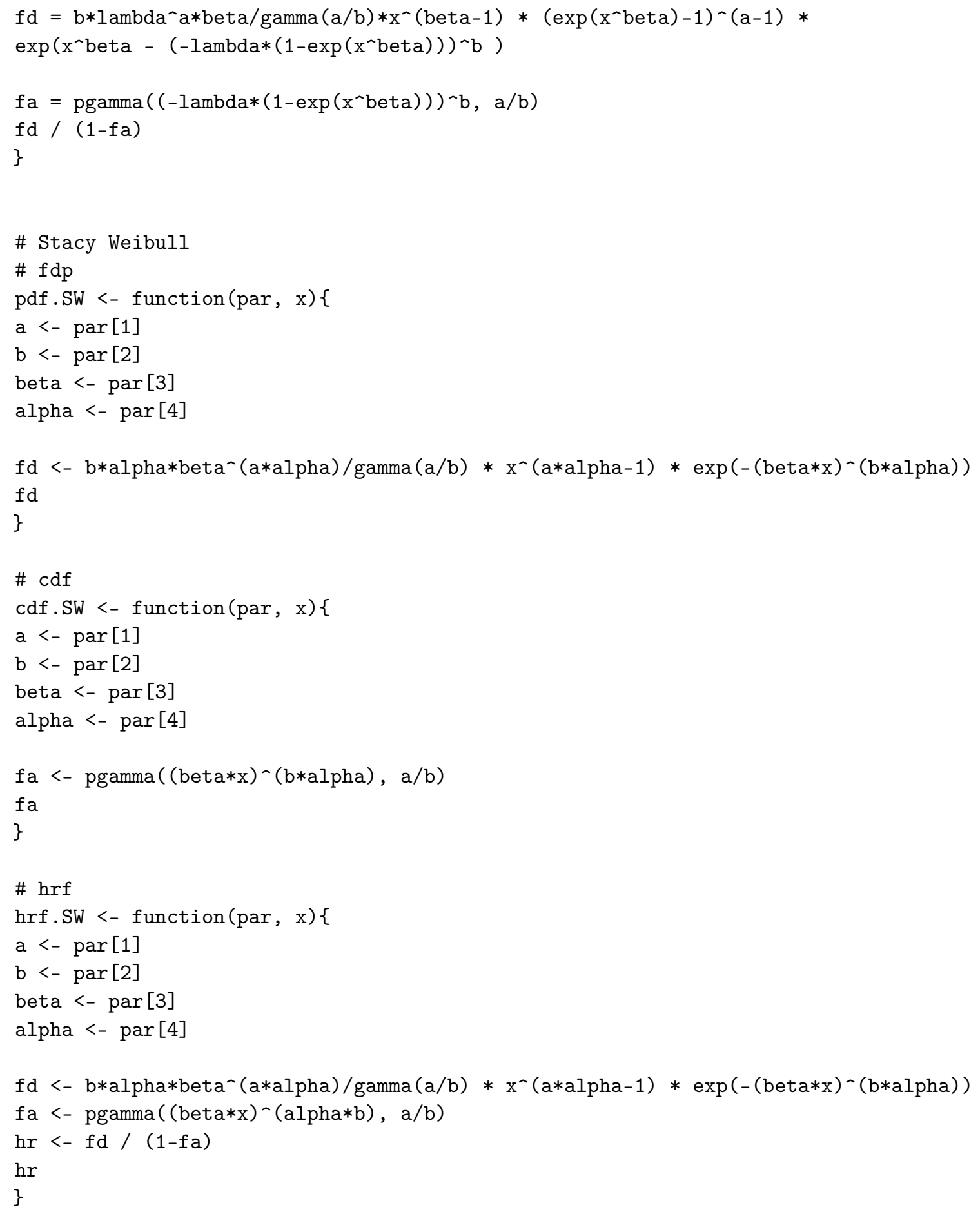


$\operatorname{par}($ new $=\mathrm{T})$

curve (pdf.SBXII $(c(.4,2,1.2, .7,2.5), x), x \lim =c(0,4), \operatorname{col}=2, \mathrm{n}=2000$, axes $=F$, ann=F, lwd=1.5, 1 ty=2) $\operatorname{par}(n e w=T)$

curve (pdf.SBXII (c(3.8,.7,1.2,.7,2.5),x), xlim =c(0,58), col=3, n=2000, axes=F, ann=F, lwd=1.5, lty=3) $\operatorname{par}(n e w=T)$

curve (pdf.SBXII $(c(1.5, .2,1.2, .7,2.5), x), x \operatorname{sim}=c(0,10), \operatorname{col}=4, n=2000$, axes=F, ann=F, 1 wd=1.5, 1 ty=4) $\operatorname{par}($ new $=\mathrm{T})$

curve (pdf.SBXII $(c(.8,1.5,1.2, .7,2.5), x), x l i m=c(0,8), \operatorname{col}=5, n=2000$, axes $=F$, ann $=F, l w d=1.5,1 t y=5)$

legend ("topright", legend $=c($ expression (paste $(a==2.7$, " ", " ", " ", b==2.2)),

expression(paste $(a==.4, "$ ", " ", " ", b==2)),

expression (paste $(a==3.8, "$ ", " ", " ", b==.7)),

expression(paste $(a==1.5, "$ ", " ", " ", $b==.2))$,

expression (paste $(a==.8, "$ ", " ", " ", $b==1.5))$ ),

$1 w d=1.5$, bty $=" n ", \operatorname{col}=1: 5,1$ ty $=1: 5$ )

\}

\# SUnif

\{

curve (pdf.SUnif $(c(2.1,3.7,0,8), x), x l i m=c(0,8), \operatorname{col}=1, n=2000, y l a b=$ "pdf", lwd=1.5, 1 ty=1) $\operatorname{par}(n e w=T)$

curve (pdf. SUnif $(c(.9,2.9,0,8), x)$, xlim $=c(0,8), \operatorname{col}=2, n=2000$, axes $=F$, ann=F, lwd=1.5, lty=2) $\operatorname{par}(n e w=T)$

curve (pdf.SUnif $(c(.8,1.1,0,8), x), x \lim =c(0,8), \operatorname{col}=3, n=2000$, axes=F, ann=F, lwd=1.5, lty=3) $\operatorname{par}($ new $=\mathrm{T})$

curve (pdf. SUnif $(c(1.6,1.6,0,8), x), x \lim =c(0,8), \operatorname{col}=4, n=2000$, axes=F, ann=F, $1 w d=1.5,1 t y=4)$ $\operatorname{par}($ new $=\mathrm{T})$

curve (pdf.SUnif $(c(1.1, .9,0,8), x)$, xlim $=c(0,8), \operatorname{col}=5, n=2000$, axes=F, ann=F, lwd=1.5, lty=5)

legend $(.2, .64$, legend $=c($ expression $(\operatorname{paste}(a==2.1, "$ ", " ", " ", b==3.7)),

expression (paste (a==.9," ", " ", " ", b==2.9)),

expression (paste $(a==.8, "$ ", " ", " ", b==1.1)),

expression (paste $(a==1.6, "$ ", " ", " ", b==1.6)),

expression (paste $(a==1.1, "$ ", " ", " ", b==.9))),

$1 w d=1.5$, bty $=" n ", \operatorname{col}=1: 5, \operatorname{lty}=1: 5)$

\}

\# SC

\{

curve (pdf.SC(c(.6,.2,1.7,1.3),x), xlim $=c(0,9), \operatorname{col}=1, n=2000, y l a b=" p d f ", 1 w d=1.5,1 t y=1)$ $\operatorname{par}(n e w=T)$

curve $(\operatorname{pdf} . \mathrm{SC}(\mathrm{c}(1.6, .4,1.7,1.3), \mathrm{x}), \mathrm{xlim}=\mathrm{c}(0,15), \mathrm{col}=2, \mathrm{n}=2000$, axes $=\mathrm{F}$, ann=F, $1 \mathrm{wd}=1.5,1 \mathrm{ty}=2)$ $\operatorname{par}($ new $=\mathrm{T})$

curve (pdf.SC $(c(.3, .1,1.7,1.3), x), x \lim =c(0,15), \operatorname{col}=3, n=2000$, axes=F, ann=F, 1 wd=1.5, lty=3) $\operatorname{par}(n e w=T)$

curve $(\operatorname{pdf} . \operatorname{SC}(c(.6,1.2,1.7,1.3), x), x \lim =c(0,5), \operatorname{col}=4, n=2000$, axes=F, ann=F, $1 \mathrm{wd}=1.5,1 \mathrm{ty}=4)$ 
$\operatorname{par}($ new $=\mathrm{T})$

curve $(\operatorname{pdf} . \mathrm{SC}(\mathrm{c}(2.1, .2,1.7,1.3), \mathrm{x}), \mathrm{xlim}=\mathrm{c}(0,15), \mathrm{col}=5, \mathrm{n}=2000$, axes=F, ann=F, $1 \mathrm{wd}=1.5,1 \mathrm{ty}=5)$

legend ("topright", legend = c(expression(paste $(a==.6, "$ ", " ", " ", b==.2)),

expression (paste $(a==1.6, "$ ", " ", " ", $b==.4)$ ),

expression (paste $(a==.3, "$ ", " ", " ", b==.1)),

expression(paste (a==.6," ", " ", " ", b==1.2)),

expression (paste $(a==2.1, "$ ", " ", " ", $b==.2))$ ),

$1 w d=1.5$, bty $=" n ", \operatorname{col}=1: 5, \operatorname{lty}=1: 5)$

\}

\# SW

\{

curve (pdf.SW $(c(1.2,1.2, .5,1.7), x), x \lim =c(0,12), \operatorname{col}=1, \mathrm{n}=2000, \mathrm{ylab}=$ "pdf", $1 \mathrm{wd}=1.5,1 \mathrm{ty}=1)$ $\operatorname{par}(n e w=T)$

curve (pdf.SW $(c(3.2, .6, .5,1.7), x), x \lim =c(0,15), \operatorname{col}=2, n=2000$, axes $=F$, ann=F, 1 wd=1.5, 1 ty=2) $\operatorname{par}($ new $=\mathrm{T})$

curve (pdf.SW $(c(2.2, .8, .5,1.7), x), x l i m=c(0,12), \operatorname{col}=3, n=2000$, axes=F, ann=F, lwd=1.5, lty=3) $\operatorname{par}($ new $=\mathrm{T})$

curve $(\operatorname{pdf} . \mathrm{SW}(\mathrm{c}(.9, .4, .5,1.7), \mathrm{x}), \mathrm{xlim}=\mathrm{c}(0,12), \mathrm{col}=4, \mathrm{n}=2000$, axes $=\mathrm{F}$, ann=F, $1 \mathrm{wd}=1.5,1 \mathrm{ty}=4)$ $\operatorname{par}(n e w=T)$

curve $(\operatorname{pdf} . \mathrm{SW}(\mathrm{c}(.5,2.5, .5,1.7), \mathrm{x}), \mathrm{xlim}=\mathrm{c}(0,5), \mathrm{col}=5, \mathrm{n}=2000$, axes $=\mathrm{F}$, ann=F, $1 \mathrm{wd}=1.5,1 \mathrm{ty}=5)$

legend $(2.8,1.1$, legend $=c($ expression $($ paste $(a==1.2, "$ ", " ", " ", b==1.2)),

expression(paste $(a==3.2, "$ ", " ", " ", b==.6)),

expression(paste $(a==2.2, "$ ", " ", " ", $b==.8)$ ),

expression (paste $(a==.9, "$ ", " ", " ", $b==.4))$,

expression (paste $(a==.5, "$ ", " ", " ", $b==2.5))$ ),

lwd=1.5, bty $=" n ", \operatorname{col}=1: 5, \operatorname{lty}=1: 5)$

\}

\# hrfs curves

\# SBXII

\{

curve (hrf.SBXII $(c(.3, .4,1.9, .4,2.2), x), x \operatorname{xim}=c(0,12), \operatorname{col}=1, \mathrm{n}=200, \mathrm{ylab}=$ "pdf", lwd=1.5, lty=1) $\operatorname{par}($ new $=\mathrm{T})$

curve $(\operatorname{hrf} . \operatorname{SBXII}(c(.1,4.5,1.9, .4,2.2), \mathrm{x}), \mathrm{xlim}=c(0,12), \mathrm{col}=2, \mathrm{n}=200$, axes=F, ann=F, lwd=1.5, lty=2) $\operatorname{par}(n e w=T)$

curve $(h r f . \operatorname{SBXII}(c(.8,1.3,1.9, .4,2.2), \mathrm{x}), \mathrm{xlim}=\mathrm{c}(0,12), \mathrm{col}=3, \mathrm{n}=200$, axes $=\mathrm{F}$, ann=F, $1 \mathrm{wd}=1.5,1 \mathrm{ty}=3)$ $\operatorname{par}(n e w=T)$

curve $(h r f . \operatorname{SBXII}(c(3.4,3.7,1.9, .4,2.2), \mathrm{x}), \mathrm{xlim}=c(0,12), \operatorname{col}=4, \mathrm{n}=200$, axes=F, ann=F, $1 \mathrm{wd}=1.5,1 \mathrm{ty}=4)$

legend $(.75, .74$, legend $=c$ (expression (paste $(a==.3, "$ ", " ", " ", b==.4)),

expression (paste $(a==.1$, ", " ", " ", b==4.5)),

expression(paste $(a==.8, "$ ", " ", " ", b==1.3)), 
expression (paste $(a==3.4, "$ ", " ", " ", $b==3.7))$ ),

$1 w d=1.5$, bty $=$ "n", $\operatorname{col}=1: 4, \operatorname{lty}=1: 4)$

\}

\# SW

\{

curve $(\operatorname{hrf} . \operatorname{SW}(c(.6, .4, .7,1.5), \mathrm{x}), \mathrm{xlim}=\mathrm{c}(0,8), \operatorname{col}=1, \mathrm{n}=200, \mathrm{ylab}=$ "pdf", lwd=1.5, $1 \mathrm{ty}=1)$ $\operatorname{par}(n e w=T)$

curve $(\operatorname{hrf} . \operatorname{SW}(c(.8, .9, .7,1.5), \mathrm{x}), \mathrm{xlim}=\mathrm{c}(0,8), \operatorname{col}=2, \mathrm{n}=200$, axes=F, ann=F, $1 \mathrm{wd}=1.5,1 \mathrm{ty}=2)$ $\operatorname{par}(\mathrm{new}=\mathrm{T})$

curve $(\operatorname{hrf} . \operatorname{SW}(c(.1,1.1, .7,1.5), \mathrm{x}), \mathrm{xlim}=\mathrm{c}(0,8), \mathrm{col}=3, \mathrm{n}=200, \mathrm{axes}=\mathrm{F}, \mathrm{ann}=\mathrm{F}, \mathrm{lwd}=1.5,1 \mathrm{ty}=3)$ $\operatorname{par}(n e w=T)$

curve $(\operatorname{hrf} . \mathrm{SW}(\mathrm{c}(.9, .3, .7,1.5), \mathrm{x}), \mathrm{xlim}=\mathrm{c}(0,8), \mathrm{col}=4, \mathrm{n}=200$, axes=F, ann=F, $1 \mathrm{wd}=1.5, \mathrm{lty}=4)$ \#par (new=T)

\#curve (hrf.SW $(c(.6, .4, .7,1.5), \mathrm{x}), \mathrm{xlim}=\mathrm{c}(0,8), \mathrm{col}=7, \mathrm{n}=200, \mathrm{axes}=\mathrm{F}, \mathrm{ann}=\mathrm{F})$

legend $(.6, .061$, legend $=c($ expression (paste $(a==.6, "$ ", " ", " ", b==.4)),

expression (paste $(a==.8, "$ ", " ", " ", $b==.9))$,

expression(paste ( $a==.1, "$ ", " ", " ", b==1.1)),

expression (paste $(a==.9, "$ ", " ", " ", $b==.3))$ ),

$1 w d=1.5$, bty $=" n ", \operatorname{col}=1: 4,1 t y=1: 4)$

\}

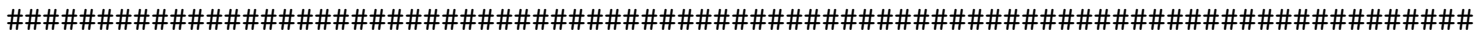

\#\#\#\#\#\#\#\#\#\#\#\#\#\#\#\#\#\#\# Assimetria e kurtose da SW \#\#\#\#\#\#\#\#\#\#\#\#\#\#\#\#\#\#

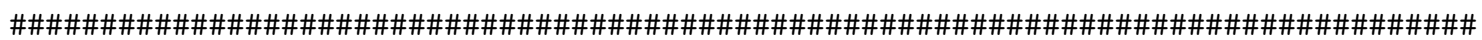

\# momentos centrais

\# UWW distribution

momcentral_SW <- function(param, r) \{

mu1 <- pdf.SW <- function (x, par=param $)\{$

a $<-\operatorname{par}[1]$

b <- par [2]

beta <- par [3]

alpha <- par [4]

fd <- b*alpha*beta^(a*alpha)/gamma(a/b) * x^(a*alpha-1) * exp (- (beta*x)^(b*alpha))

fd

\}

meanx <- integrate (mu1, 0, Inf, subdivisions = 1e6)\$value

mu2. central <- function $(x$, par=param, mu=meanx $)\{$ 


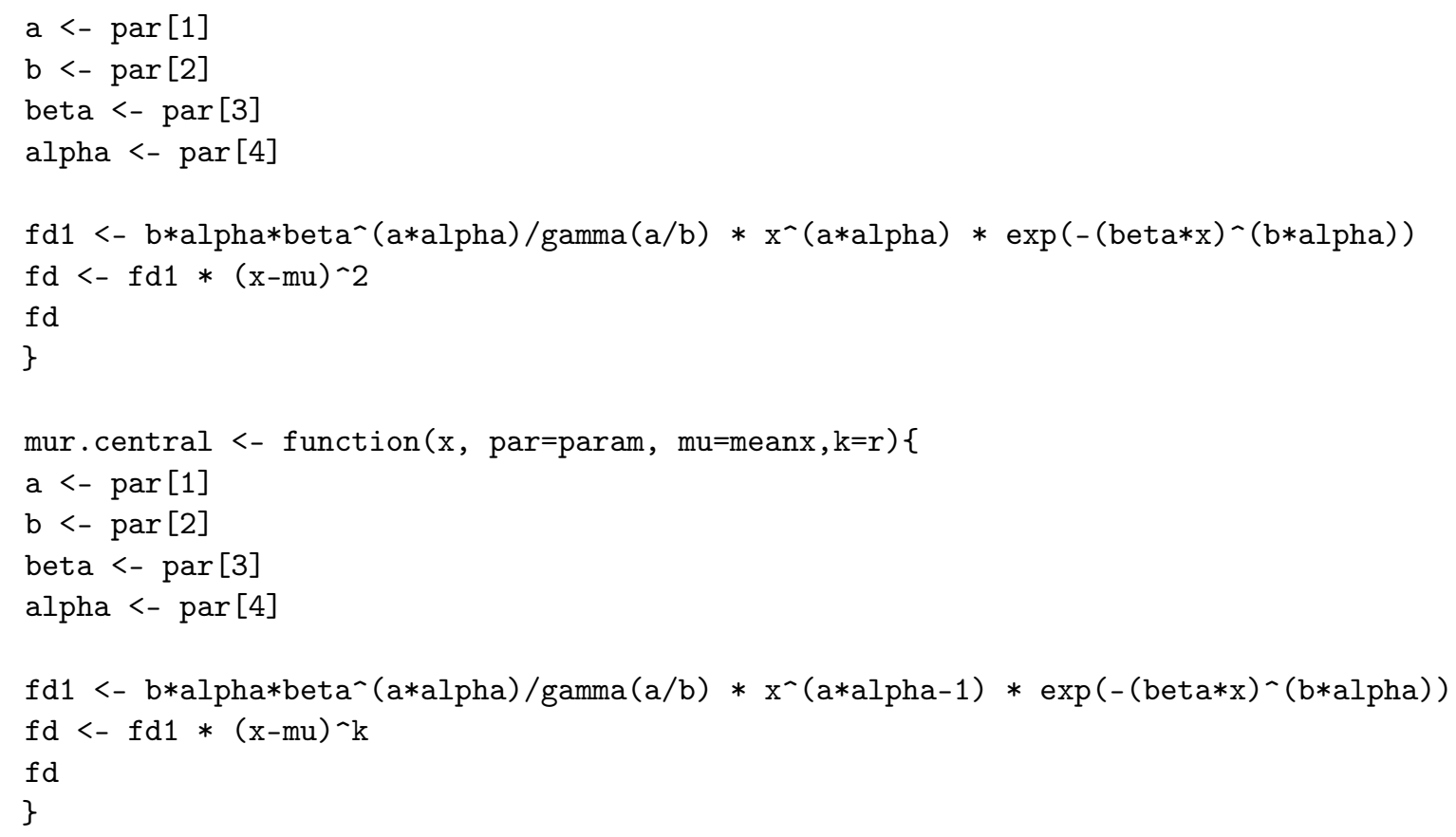




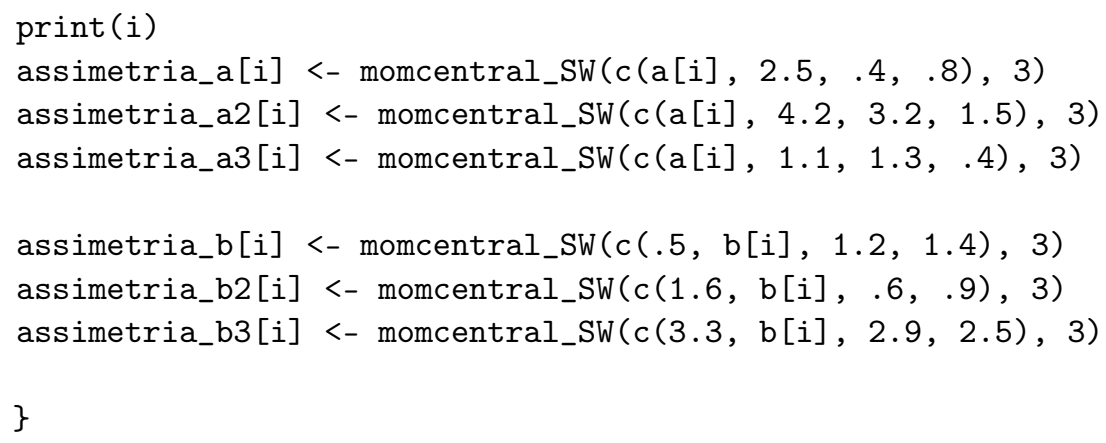




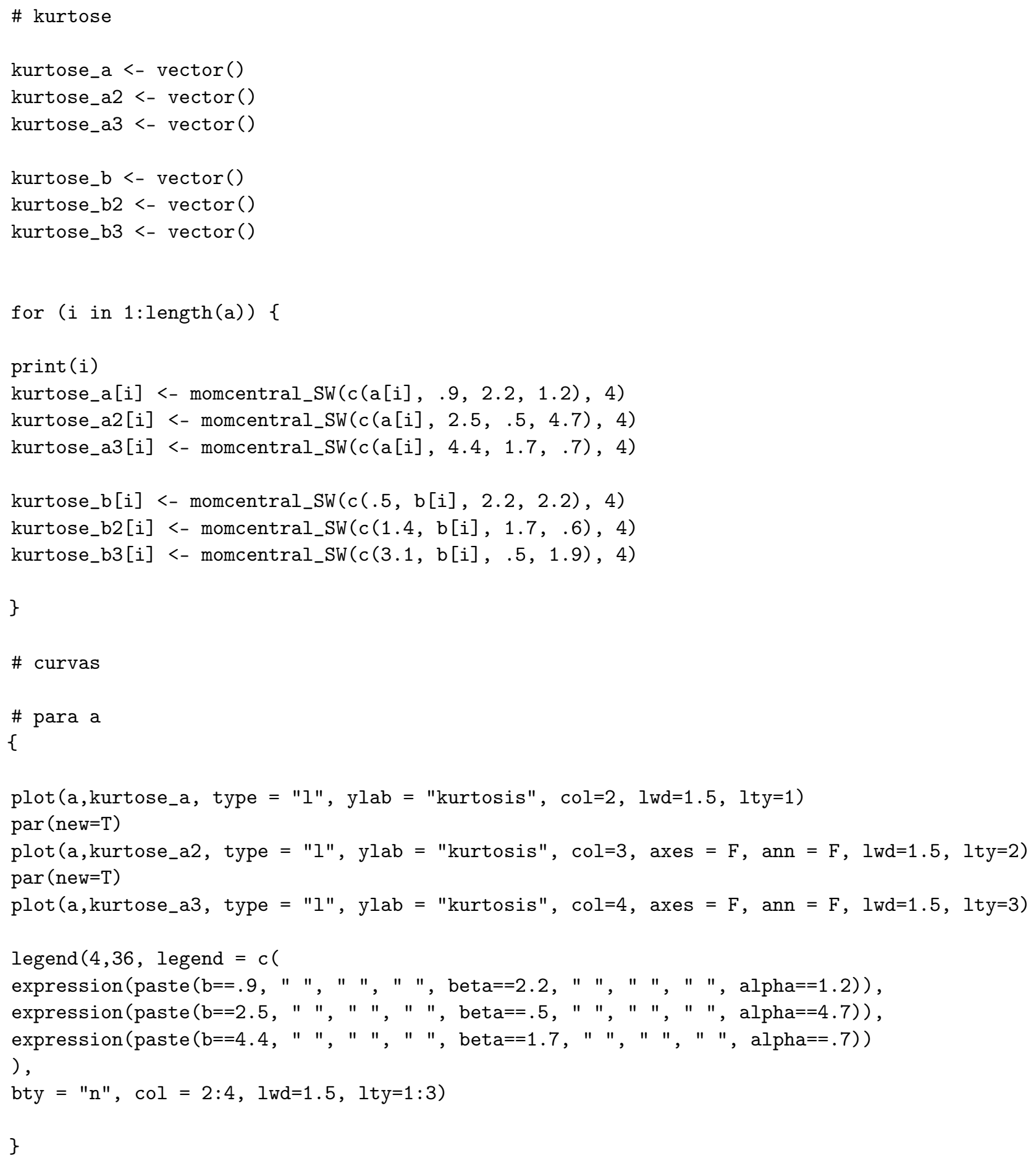




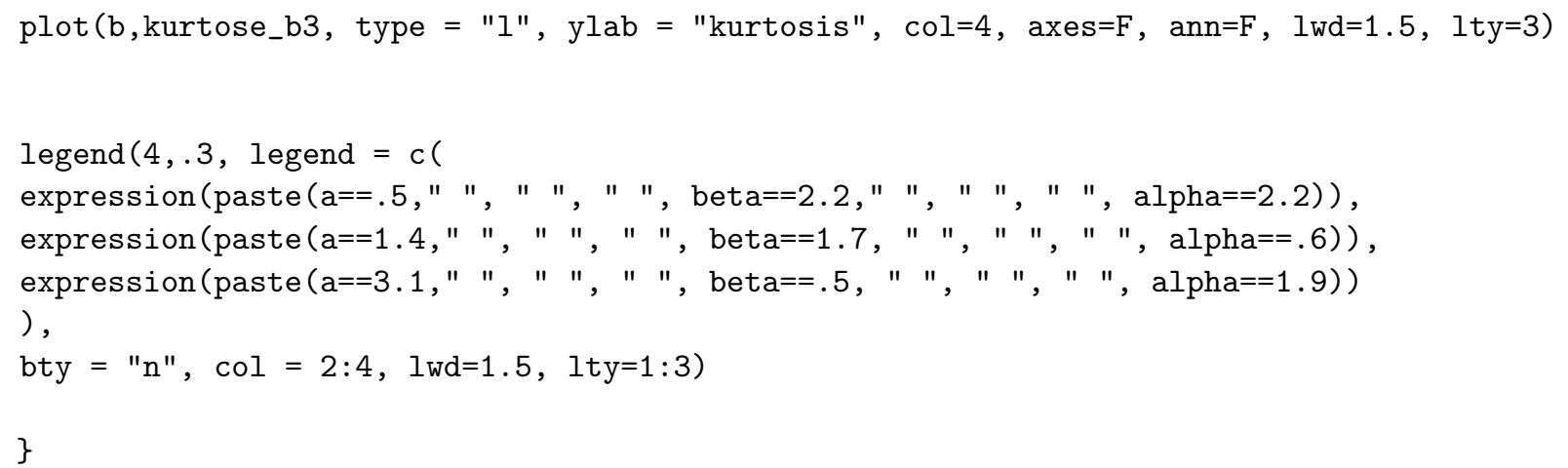

Appendix A.2. Simulation (Ox Code)

\#include <oxstd.oxh>

\#include <oxprob.oxh>

\#import <maximize>

static decl $\mathrm{x}$;

// quantile function

quantile_funtion(const par, const $u$ )

\{

$\operatorname{decl} \mathrm{a}=\operatorname{par}[0], \mathrm{b}=\operatorname{par}[1]$, lambda $=\operatorname{par}[2]$, beta $=\operatorname{par}[3], \mathrm{qv}, \mathrm{fd} ;$

$\mathrm{qv}=1-\exp \left(\right.$-quangamma $\left.(\mathrm{u}, \mathrm{a} / \mathrm{b}, 1) \cdot \cdot^{-}(1 / \mathrm{b})\right) ;$

$f d=\log (1-\log (1-q v) / \operatorname{lambda}) \cdot{ }^{-}(1 /$ beta $) ;$

return $f d$;

\}

\section{// likelihood}

Likelihood(const par, const adFunc, const avScore, const amHess)

\{

$\operatorname{decl} \mathrm{a}=\operatorname{par}[0], \mathrm{b}=\operatorname{par}[1], \operatorname{lambda}=\operatorname{par}[2]$, beta $=\operatorname{par}[3], \mathrm{fd} ;$

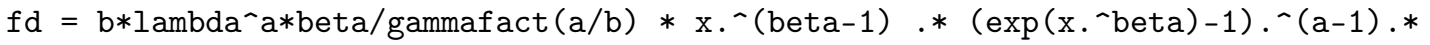

$\exp \left(\mathrm{x} .{ }^{\wedge} \operatorname{beta}-\left(-\operatorname{lambda} *\left(1-\exp \left(\mathrm{x} \cdot{ }^{\wedge}\right.\right.\right.\right.$ beta $\left.\left.\left.)\right)\right) \cdot \wedge \mathrm{b}\right)$;

$\operatorname{adFunc}[0]=\operatorname{sumc}(\log (f d))$;

if (isnan(adFunc [0]) || isdotinf (adFunc[0]))

return 0 ;

else

return 1;

\}

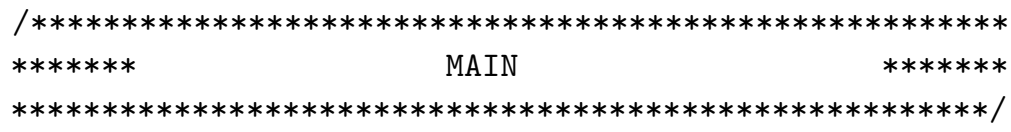

$\operatorname{main}()$

\{

$\operatorname{decl} \mathrm{n}=300 ; / / 50,100,150,200,300$ 
decl NREP $=5000 ; / /$ number of Monte Carlo replicas

decl par $=\langle .5, .9, .4,1.6\rangle$; // true parameters

decl $j=0$, failures $=0$, start_time, exec_time;

decl vp, dfunc, opt, random, vep, hessiana, intervals;

decl mMLE $=\operatorname{zeros}($ NREP, $\operatorname{rows}($ par') ), mean_MLE, bias_MLE, mse_MLE, results;

ranseed("MWC_32"); // gerador de numeros aleatorios

ranseed (2002);

// quantis standard normal

decl z5 = quann $(.975) ; / / 5 \%$

// counter of interval and interval lenght

decl CI95, maxMLE, minMLE;

CI95 $=\operatorname{zeros}(1, \operatorname{rows}($ par' $)) ; / /$

$\operatorname{maxMLE}=\operatorname{minMLE}=\operatorname{zeros}\left(\right.$ NREP, $\left.\operatorname{rows}\left(\operatorname{par}{ }^{\prime}\right)\right)$;

// starting chronometer

start_time $=$ timer () ;

// initial Monte Carlo loop

while $(j<$ NREP $)$

\{

// generating random numbers

random = quantile_funtion $(\operatorname{par}, \operatorname{ranu}(n, 1))$;

$\mathrm{x}=$ random;

// starting kicks

$\mathrm{vp}=\langle 1 ; 1 ; 1 ; 1\rangle$;

MaxControl $(50,-1)$;

opt $=$ MaxBFGS(Likelihood, \&vp, \&dfunc, 0, 1);

// testing convergence

if (opt $==0||$ opt $==1$ )

\{

$\operatorname{mMLE}[j][0]=\mathrm{vp}[0]$;

$\operatorname{mMLE}[j][1]=\operatorname{vp}[1]$;

$\operatorname{mMLE}[j][2]=\operatorname{vp}[2]$;

$\operatorname{mMLE}[j][3]=\operatorname{vp}[3]$;

// numerical observed matrix

Num2Derivative(Likelihood, vp, \&hessiana);

if ( invertsym(-hessiana) $!=0$ )

\{

// standard-erros

vep $=\operatorname{sqrt}($ diagonal $($ invertsym $(-$ hessiana $)))$;

// maximum values of the interval 


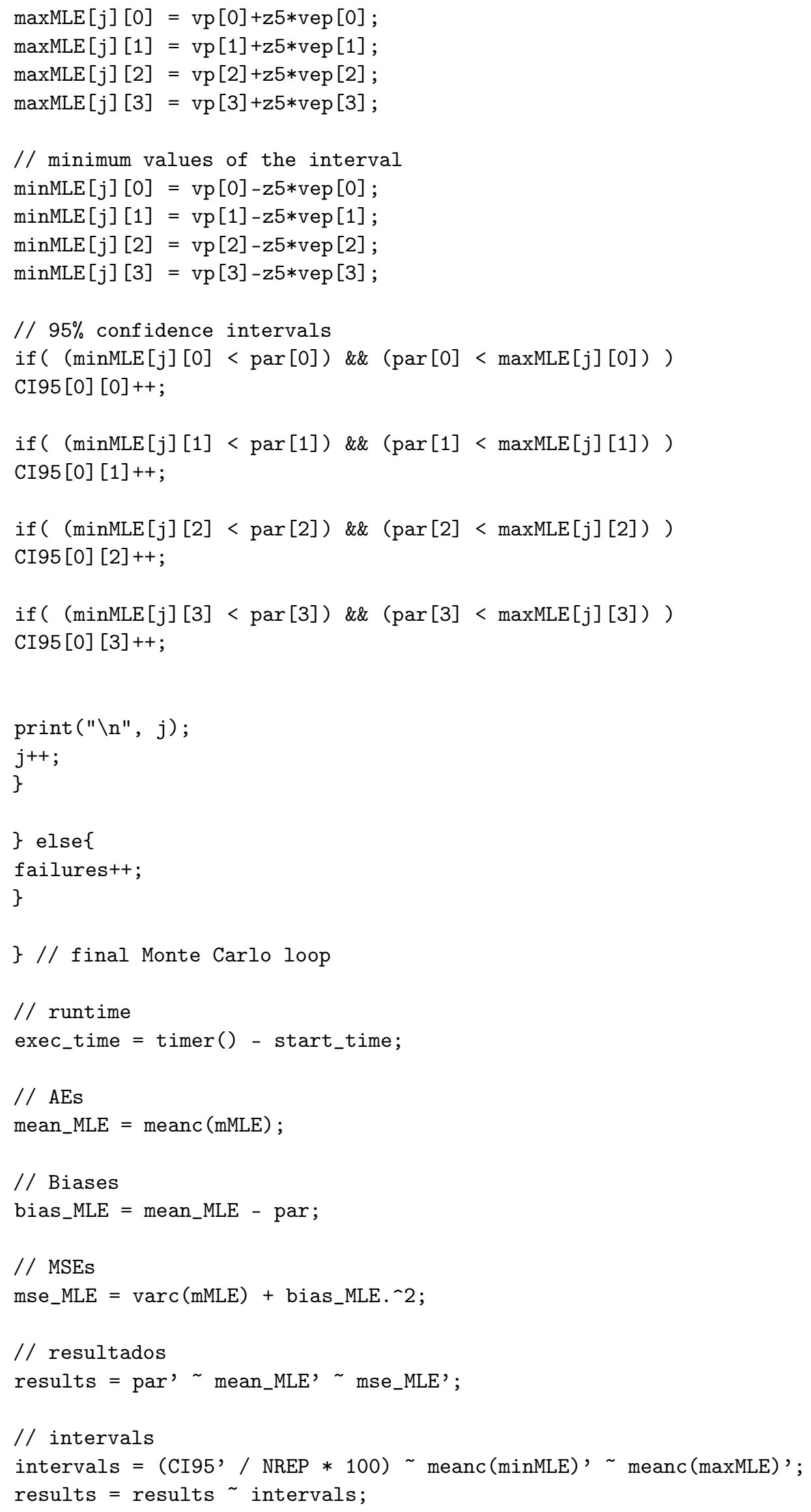




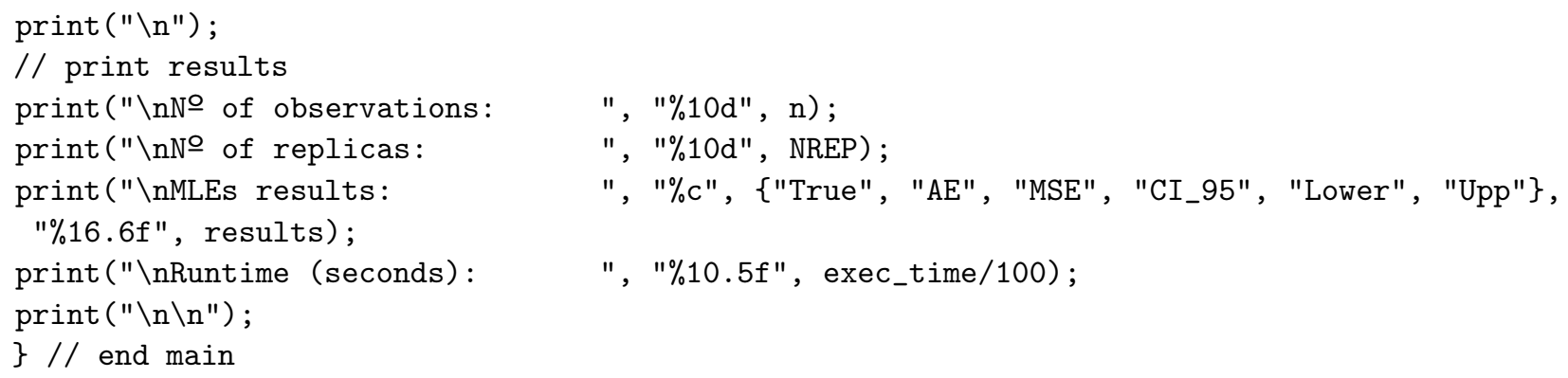

Appendix A.3. Applications Codes

Uncensored Data

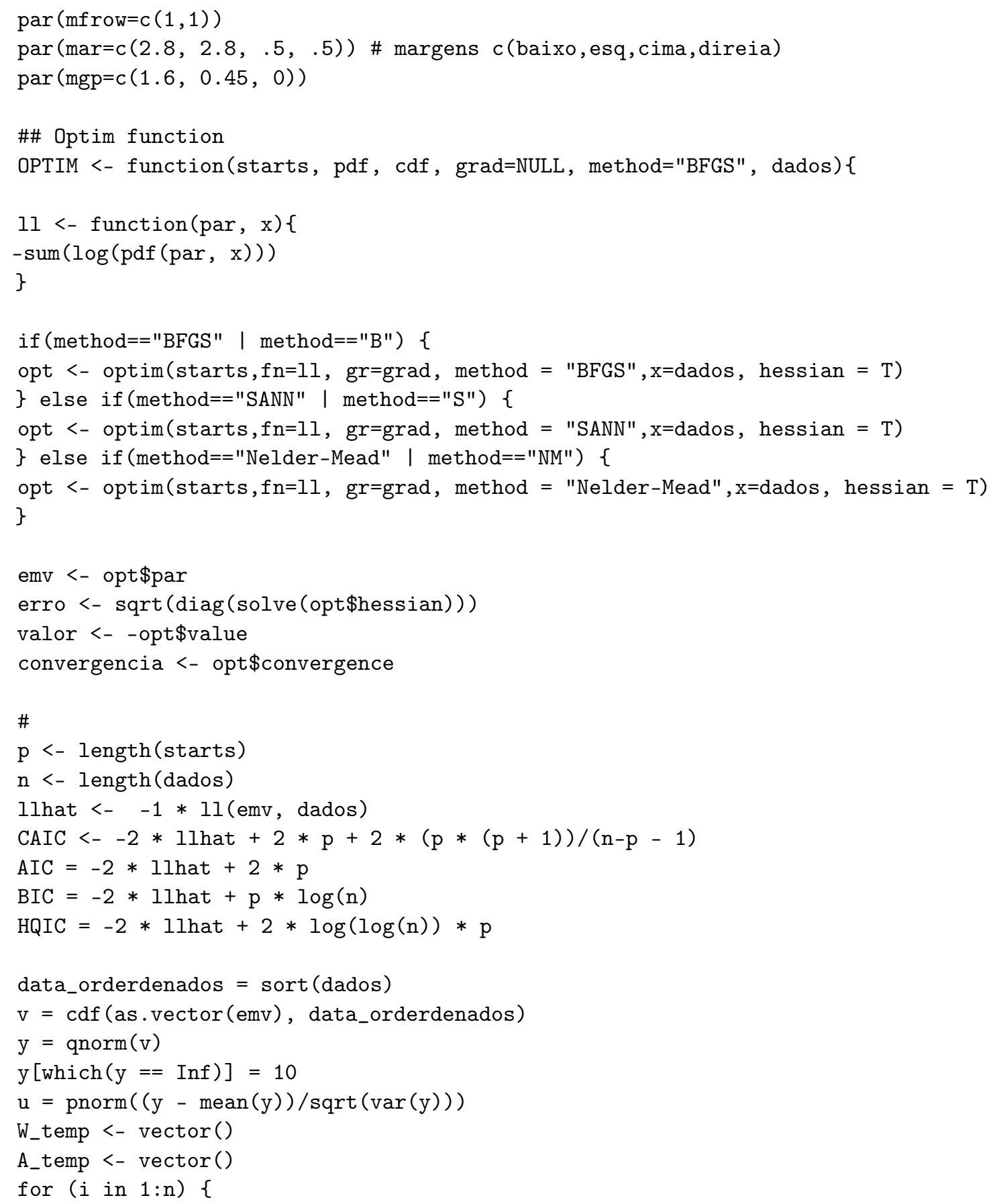




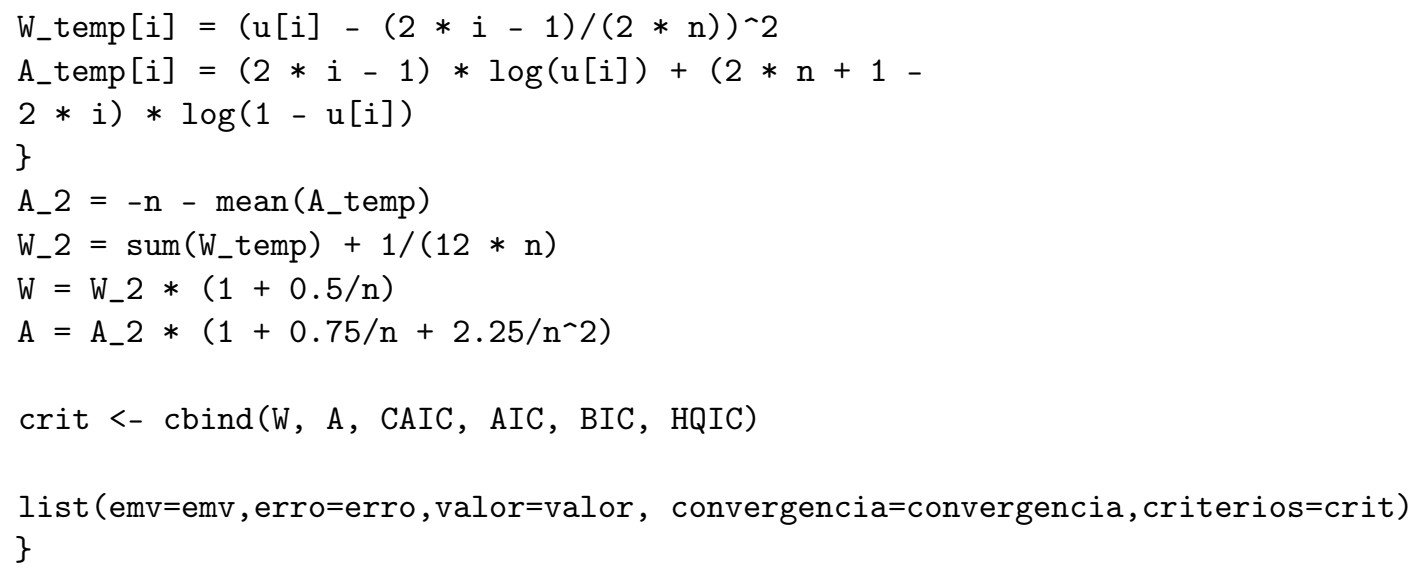




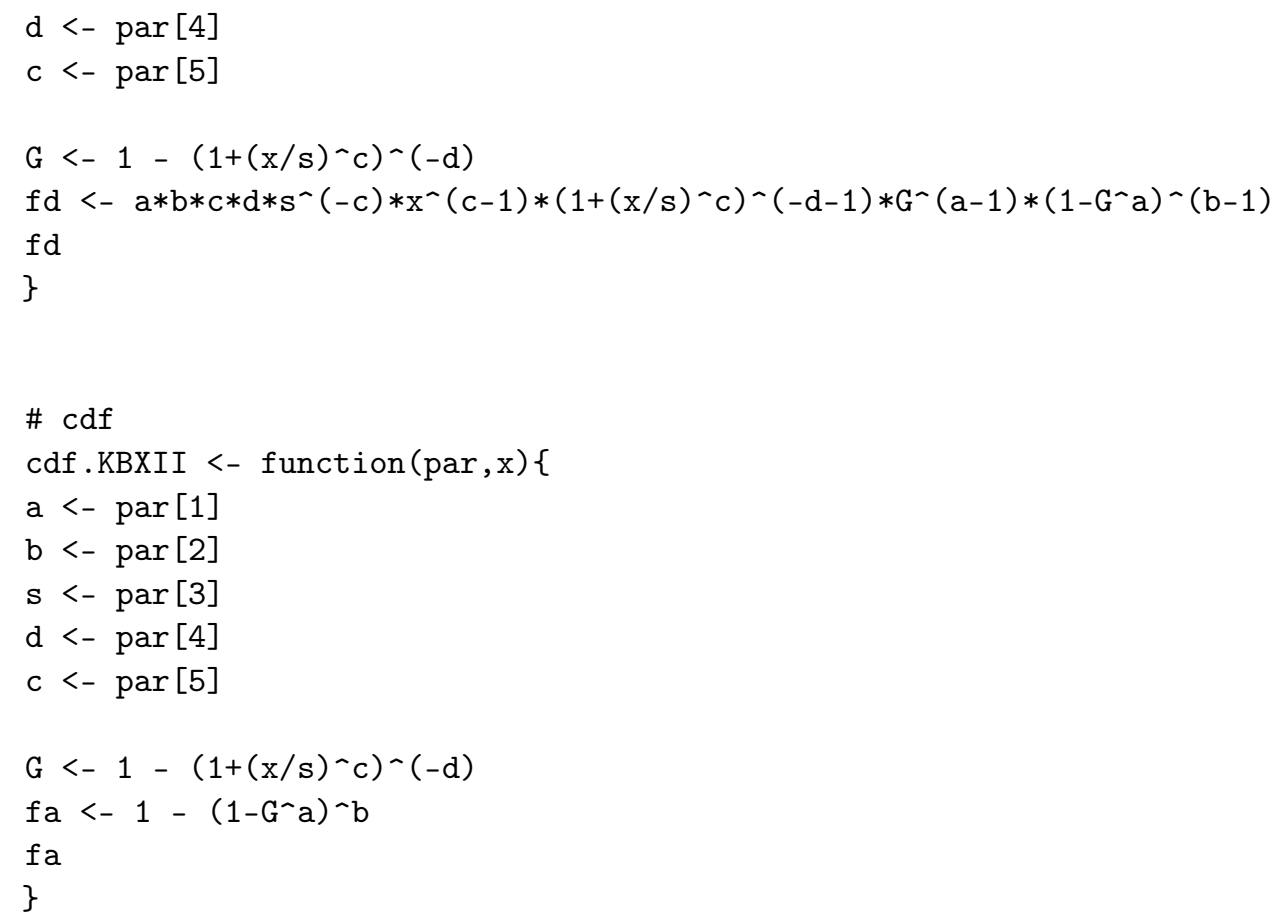


\# The odd Lomax generator of distributions: Properties,

\# estimation and applications

cordeiroetal2019<- c $(1.6,2.0,2.6,3.0,3.5,3.9,4.5,4.6,4.8,5.0,5.1,5.3,5.4$, $5.6,5.8,6.0,6.0,6.1,6.3,6.5,6.5,6.7,7.0,7.1,7.3,7.3$, $7.3,7.7,7.7,7.8,7.9,8.0,8.1,8.3,8.4,8.4,8.6,8.7$, $8.8,9.0)$

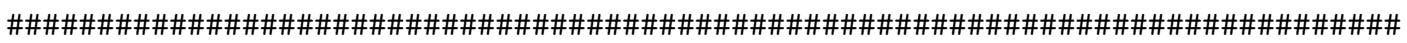

\# aplication 1

SG.dados $1<-$ hosseini

emv.SBXII <- OPTIM(c(1.1,1,1,1,1), pdf=pdf.SBXII, cdf=cdf.SBXII, dados=SG.dados1) emv.GBXII <- OPTIM(c $(1,1, .1, .1), \operatorname{pdf}=$ pdf.GBXII, cdf=cdf.GBXII, dados=SG.dados1) emv.BXII <- OPTIM $(c(.1, .1, .1), \operatorname{pdf}=p d f . B X I I, \quad c d f=c d f . B X I I$, dados=SG.dados1) emv.BBXII <- OPTIM $(c(1,1,1, .1, .1)$, pdf=pdf.BBXII, cdf=cdf.BBXII, dados=SG.dados1) emv.KBXII <- OPTIM(c(1,1,1,.1,.1), pdf=pdf.KBXII, cdf=cdf.KBXII, dados=SG.dados1) emv.WBXII <- OPTIM $(c(1,1, .1, .1), \operatorname{pdf}=\operatorname{pdf}$. WBXII, $c d f=c d f . W B X I I, d a d o s=S G . d a d o s 1)$

\# coefs

SG. coef $1<-$ rbind (

\# BXII

c(NA, NA, emv.BXII\$emv), c(NA, NA, emv.BXII\$erro),

\# GBXII

c(emv.GBXII\$emv, NA), c(emv.GBXII\$erro, NA),

\# SBXII

emv.SBXII\$emv, emv.SBXII\$erro,

\# BBXII

emv.BBXII\$emv, emv.BBXII\$erro,

\# KBXII

emv.KBXII\$emv, emv.KBXII\$erro,

\# WBXII

c (emv.WBXII\$emv, NA), c (emv.WBXII\$erro, NA)

)

rownames (SG.coef1) <- c("BXII", " ", "GBXII", " ", "SBXII", " ", "BBXII", " ", "KBXII", ", "WBXII", " ")

SG. coef 1

\# criterios

SG.criterios $1<-$ rbind (

\# BXII

emv.BXII\$criterios,

\# GBXII

emv. GBXII\$criterios,

\# SBXII

emv.SBXII\$criterios,

\# BBXII

emv.BBXII\$criterios,

\# KBXII

emv.KBXII\$criterios, 


\author{
\# WBXII \\ emv.WBXII\$criterios \\ )
}

SG.criterios1

rownames(SG.criterios1) <- c("BXII", "GBXII", "SBXII", "BBXII", "KBXII", "WBXII")

sort (SG.criterios1 $[, 1])$

sort (SG.criterios1 [,2])

\# LR TEST

$2 *$ (emv.SBXII\$valor - emv.GBXII\$valor)

$2 *$ (emv.SBXII\$valor - emv.BXII\$valor)

\# pdf

\{

hist (SG.dados1, freq $=F, x l a b=" x ", y l a b=" p d f "$, main $="$, ylim $=c(0, .019))$

curve (pdf.SBXII (emv.SBXII\$emv, x), col=3, add=T, $n=500,1$ ty=1, lwd=1.5)

curve (pdf.KBXII (emv.KBXII\$emv, x), col=2, add=T, $n=500,1$ ty=2, lwd=1.5)

legend $(110, .016,1 w d=1.5, \operatorname{col}=c(3,2)$, bty $=" n "$, legend $=c(" S B X I I "$, "KBXII"), 1 ty=1:2)

\}

\# cdf

\# kaplan-meier

\{

SGdados1_KP <- survfit(Surv(SG.dados1) 1)

plot (SGdados1_KP\$time, 1-SGdados1_KP\$surv, $x l a b=" x ", y l a b=$ "cdf", main = " , type = "s") abline $(\mathrm{h}=1, \mathrm{lty}=9)$

curve (cdf.SBXII (emv.SBXII $\$$ emv, $x$ ), $\operatorname{col}=3$, add=T, $n=500,1$ ty=1, $1 w d=1.5$ )

curve (cdf.KBXII (emv.KBXII $\$$ emv, $x$ ), $\operatorname{col}=2, \operatorname{add}=T, \mathrm{n}=500,1 \mathrm{ty}=2,1 \mathrm{wd}=1.5$ )

legend $(110, .6$, lwd $=1.5, \operatorname{col}=c(3,2)$, bty $=" n "$, legend $=c(" S B X I I "$, "KBXII" $), 1 t y=1: 2)$

\}

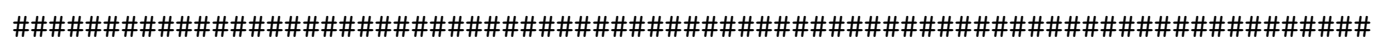

\# aplication 2

SG.dados2 <- cordeiroetal2019

emv.SBXII2 <- OPTIM(c(1.,.1,1.,1.1,.1), pdf=pdf.SBXII, cdf=cdf.SBXII, dados=SG.dados2)

emv.GBXII2 <- OPTIM $(c(1,1.1,1,1), \mathrm{pdf}=\mathrm{pdf}$.GBXII, $c d f=c d f . G B X I I$, dados=SG.dados2)

emv.BXII2 <- OPTIM $(c(.1, .1,1), \mathrm{pdf}=\mathrm{pdf}$.BXII, $c d f=c d f . B X I I$, dados=SG.dados2)

emv.BBXII2 <- OPTIM $(c(1,1,1, .1,1), \operatorname{pdf}=\operatorname{pdf}$. BBXII, $c d f=c d f . B B X I I$, dados=SG.dados2) 
emv.KBXII2 <- OPTIM $(c(1,1,1, .1, .1), \operatorname{pdf}=$ pdf.KBXII, $c d f=c d f . K B X I I$, dados=SG.dados 2$)$

emv.WBXII2 <- OPTIM $(c(1,1, .1,1), \operatorname{pdf}=p d f . W B X I I, ~ c d f=c d f . W B X I I, ~ d a d o s=S G . d a d o s 2)$

\# coefs

SG. coef $2<-$ rbind (

\# BXII

$c(N A, N A, e m v . B X I I 2 \$ e m v)$, c(NA, NA, emv.BXII2\$erro),

\# GBXII

c (emv.GBXII2\$emv, NA), c(emv.GBXII2\$erro, NA),

\# SBXII

emv.SBXII2\$emv, emv.SBXII2\$erro,

\# BBXII

emv.BBXII2\$emv, emv.BBXII2\$erro,

\# KBXII

emv.KBXII2\$emv, emv.KBXII2\$erro,

\# WBXII

c (emv.WBXII2\$emv, NA), c(emv.WBXII2\$erro, NA)

)

rownames(SG.coef2) <- c("BXII", " ", "GBXII", " ", "SBXII", " ", "BBXII", " ", "KBXII", " ", "WBXII", " ")

SG. coef 2

\# criterios

SG.criterios $2<-$ rbind (

\# BXII

emv.BXII2\$criterios,

\# GBXII

emv.GBXII2\$criterios,

\# SBXII

emv.SBXII2\$criterios,

\# BBXII

emv.BBXII2\$criterios,

\# KBXII

emv.KBXII2\$criterios,

\# WBXII

emv.WBXII2\$criterios

)

SG.criterios2

rownames(SG.criterios2)<- c("BXII", "GBXII", "SBXII", "BBXII", "KBXII", "WBXII")

SG.criterios2

sort (SG.criterios2[,1])

sort (SG.criterios2 [,2])

\# LR TEST

$2 *$ (emv.SBXII2\$valor - emv.GBXII2\$valor) 
2* (emv.SBXII2\$valor - emv.BXII2\$valor)

\author{
\# curves \\ \# pdf \\ \{
}

hist (SG.dados2, freq $=F, x l a b=" x ", y l a b=$ "pdf", main = " $)$

curve (pdf.SBXII (emv.SBXII2\$emv, x), col=3, add=T, n=500, lwd=1.5, lty=1)

curve (pdf.GBXII (emv.GBXII2\$emv, x), col=2, add=T, n=500, lwd=1.5, 1ty=2)

legend $(1.5, .19$, lwd $=1.5, \operatorname{col}=c(3,2)$, bty $=" n "$, legend $=c(" \operatorname{SBXII",} " \mathrm{GBXII} "), 1 \mathrm{ty}=1: 2)$

\}

\# cdf

\# kaplan-meier

\{

SGdados2_KP <- survfit(Surv(SG.dados2) 1)

plot (SGdados2_KP\$time, 1-SGdados2_KP\$surv, $x l a b=~ " x ", y l a b=~ " c d f "$, main = " ", type = "s") abline $(\mathrm{h}=1, \mathrm{lty}=9)$

curve (cdf.SBXII (emv.SBXII2\$emv, x), col=3, add=T, n=500, lwd=1.5, 1ty=1)

curve (cdf.GBXII (emv.GBXII2\$emv, x), col=2, add=T, n=500, lwd=1.5, 1 ty=2)

legend $(3.3, .8$, lwd $=1.5, \operatorname{col}=c(3,2)$, bty $=$ "n", legend $=c(" \operatorname{SBXII",} " \mathrm{GBXII"}), \mathrm{lty}=1: 2)$

\}

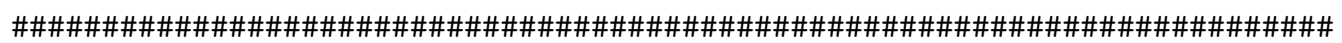

\#\#\#\#\#\#\#\#\#\#\#\# $\quad$ Figures of the likelihoods in MLEs \#\#\#\#\#\#\#\#\#\#\#\#\#\#

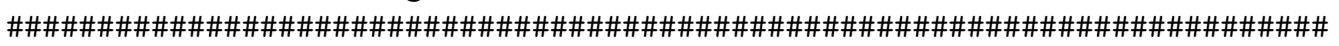

\# aplication 1

emvs $1<-$ emv.SBXII\$emv

emv. SBXII\$emv

$\mathrm{xa}<-\operatorname{seq}($ from $=.02$, to $=4$, length. out $=1000)$

$\mathrm{xb}<-\operatorname{seq}($ from $=1$, to $=10$, length. out=1000)

xs $<-\operatorname{seq}($ from $=15$, to $=50$, length. out=1000)

xd $<-\operatorname{seq}($ from $=.0014$, to $=.05$, length. out=1000)

$x c<-\operatorname{seq}($ from $=1$, to $=40$, length. out=1000)

emv_a = vector ()

emv_b = vector ()

emv_s = vector $($ )

emv_d = vector ()

emv_c $=$ vector () 


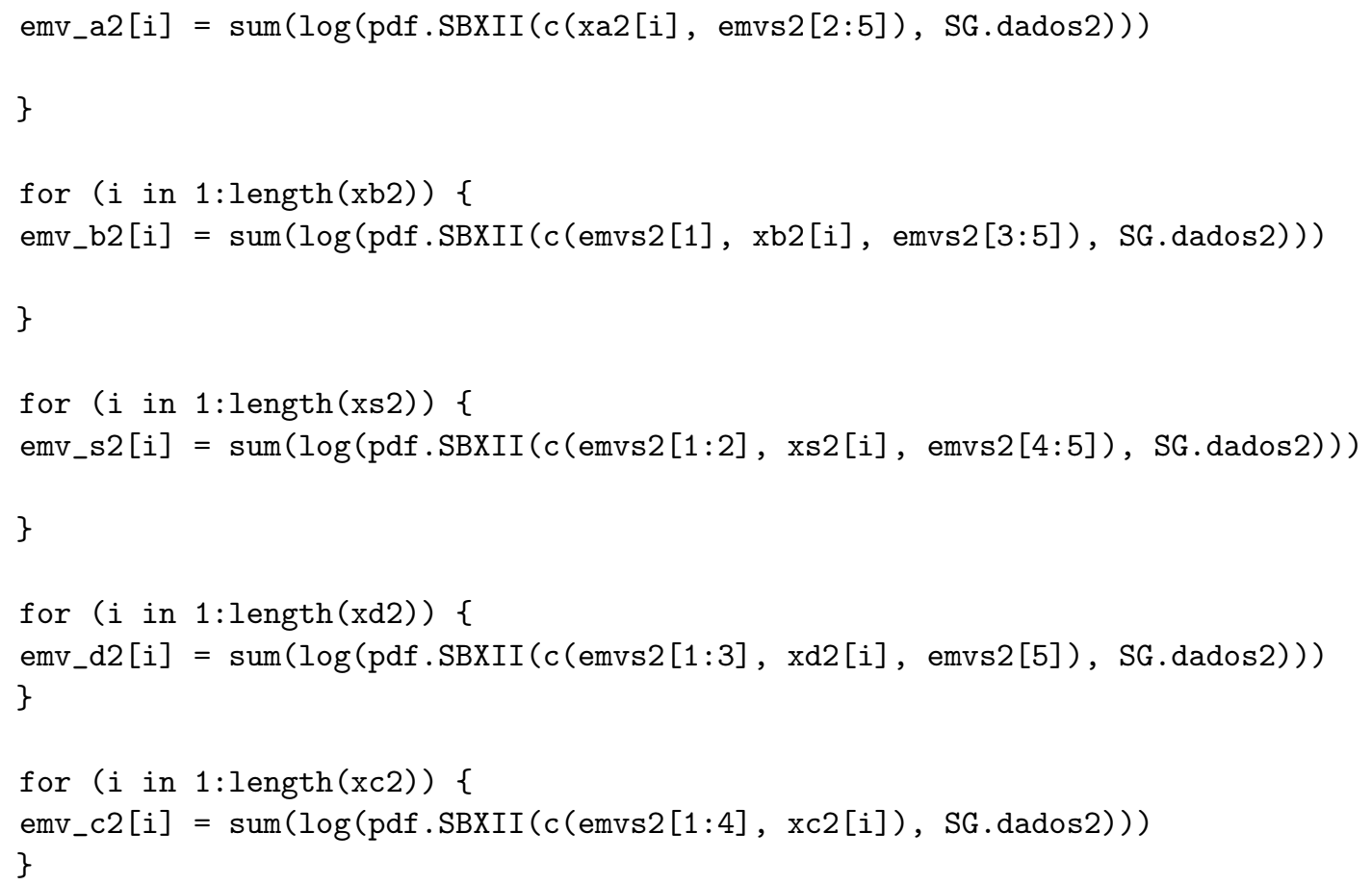




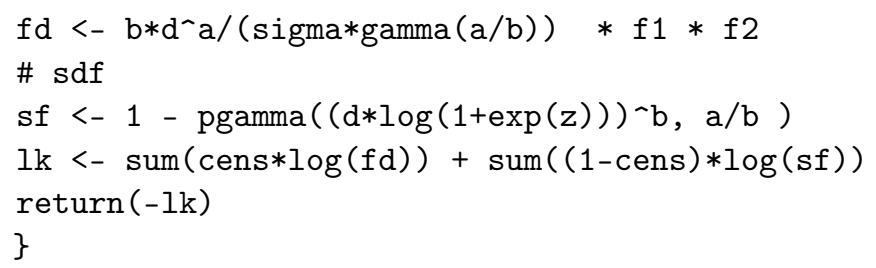




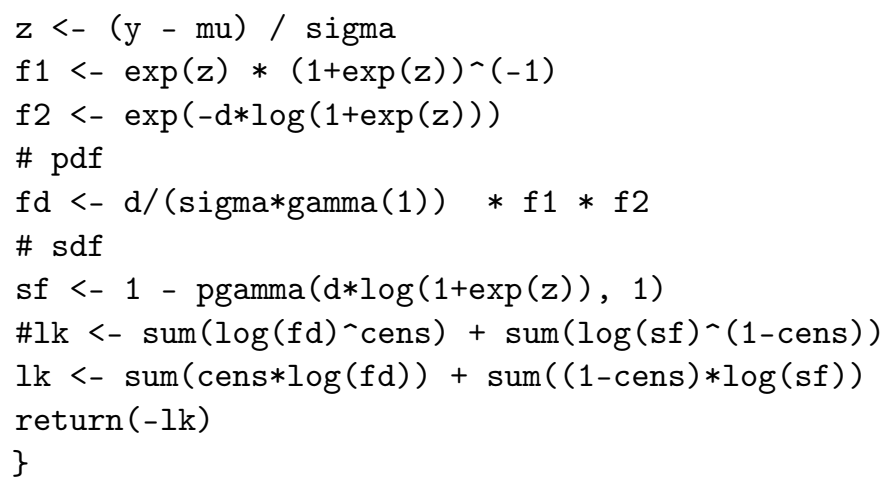




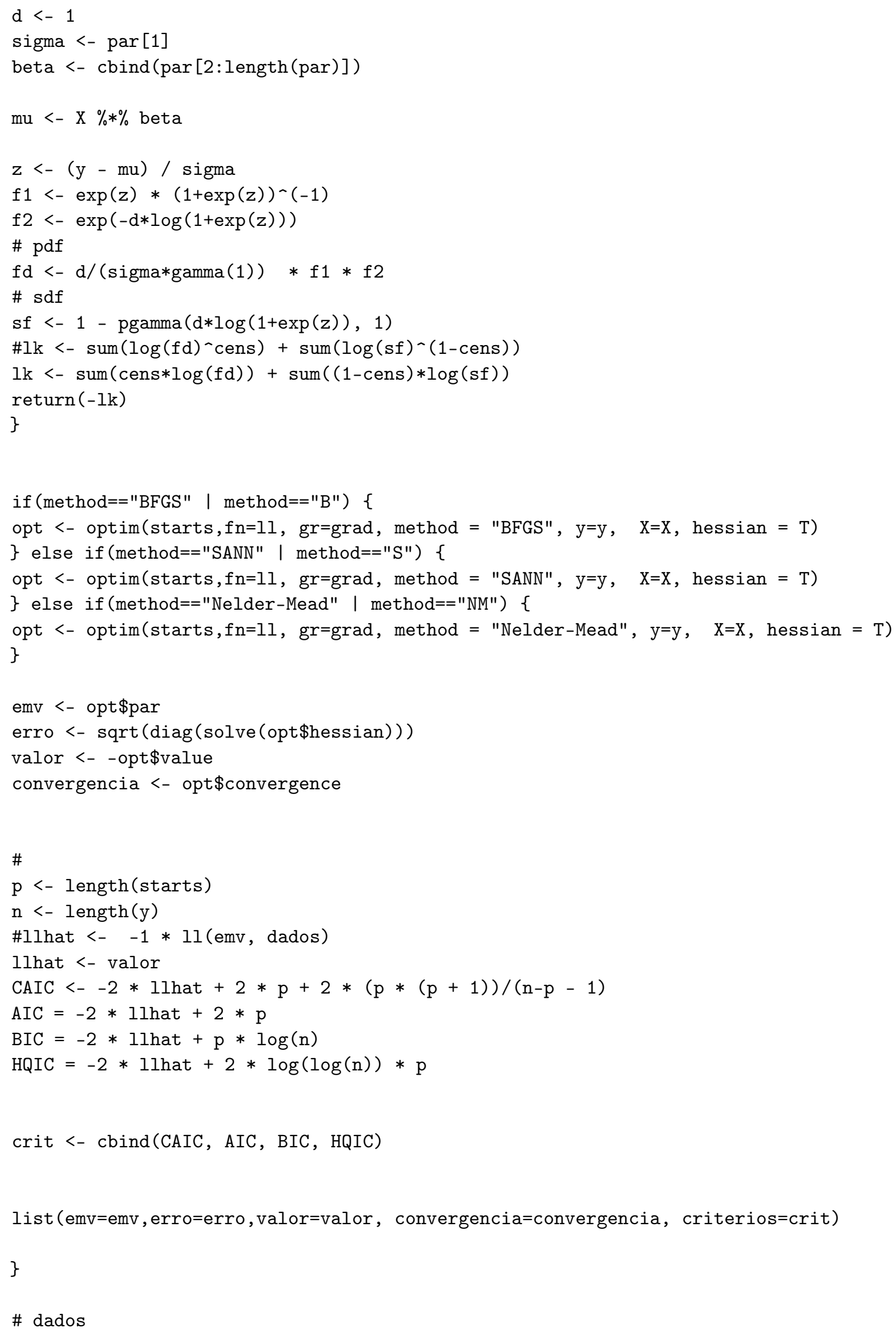




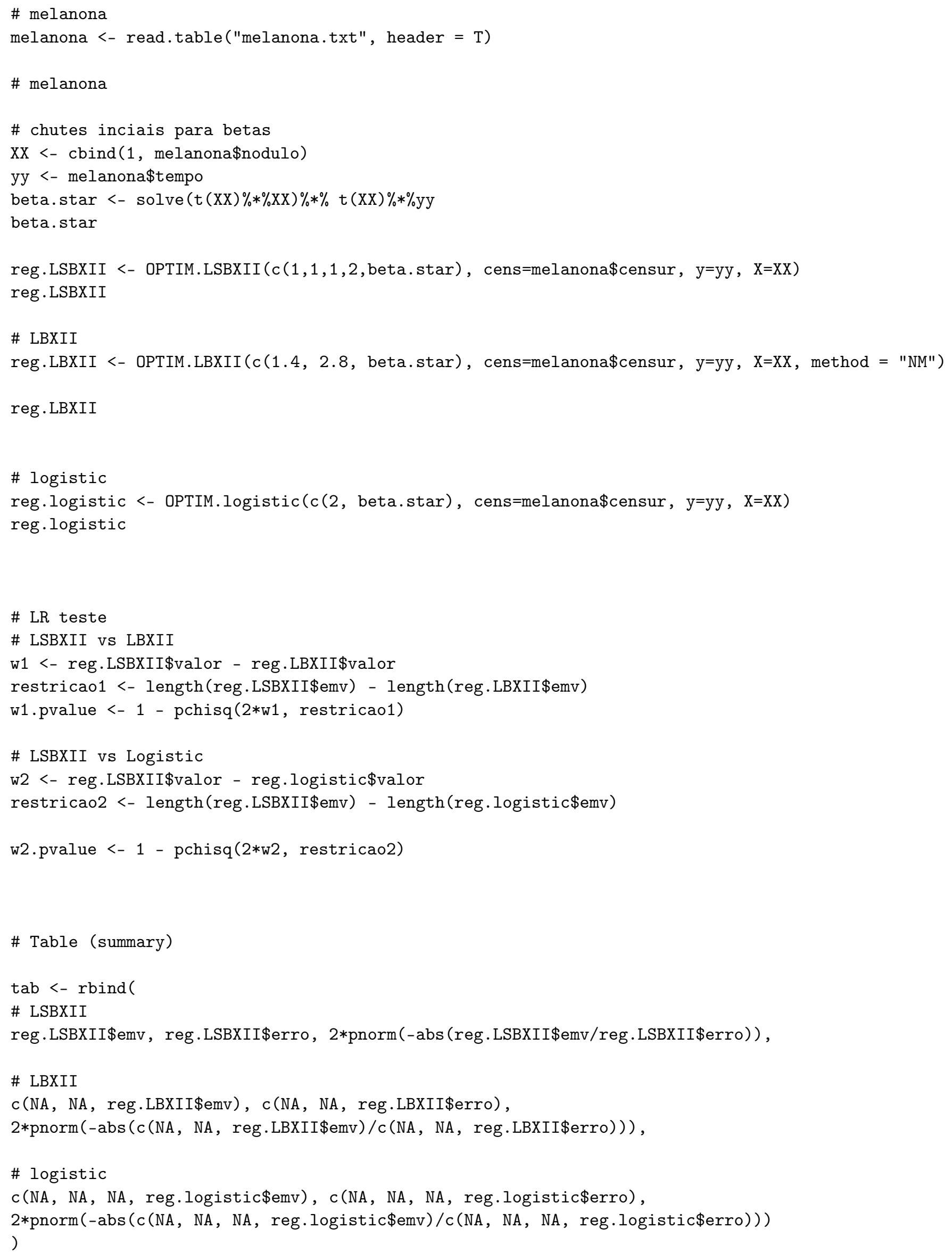




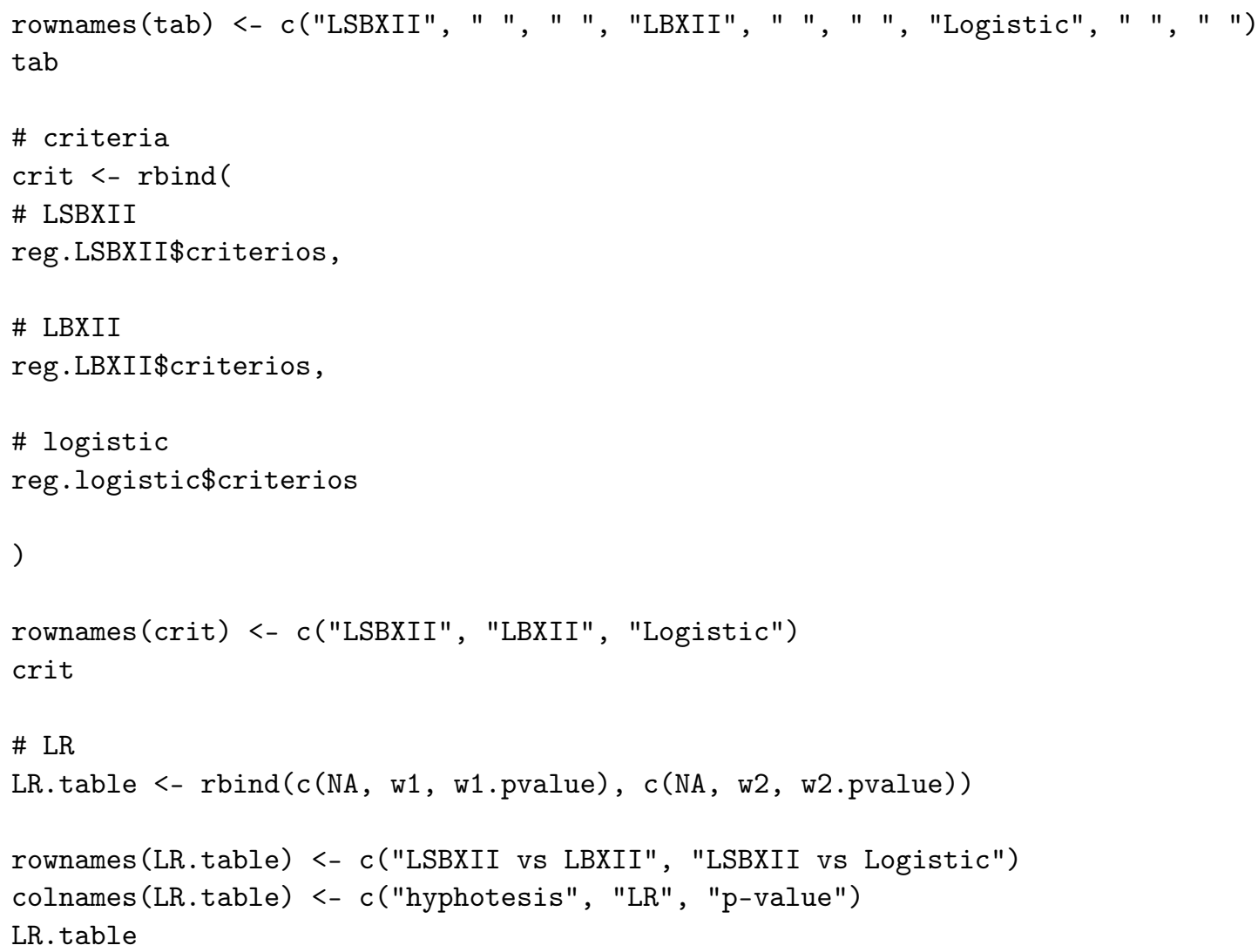

\section{References}

1. Alzaatreh, A.; Lee, C.; Famoye, F. A new method for generating families of continuous distributions. Metron 2013, 71, 63-79. [CrossRef]

2. Stacy, E.W. A generalization of the gamma distribution. Ann. Math. Stat. 1962, 33, 1187-1192. [CrossRef]

3. de Pascoa, M.A.R.; Ortega, E.M.M.; Cordeiro, G.M. The Kumaraswamy generalized gamma distribution with application in survival analysis. Stat. Methodol. 2011, 8, 411-433. [CrossRef]

4. Cordeiro, G.M.; Ortega, E.M.M.; Nadarajah, S. The Kumaraswamy Weibull distribution with application to failure data. J. Frankl. Inst. 2010, 347, 1399-1429. [CrossRef]

5. Cordeiro, G.M.; Ortega, E.M.M.; Silva, G.O. The exponentiated generalized gamma distribution with application to lifetime data. J. Stat. Comput. Simul. 2010, 81, 827-842. [CrossRef]

6. Mudholkar, G.S.; Srivastava, D.K.; Freimer, M. The exponentiated Weibull family: A reanalysis of the bus-motor-failure data. Technometrics 1995, 37, 436-445. [CrossRef]

7. Cordeiro, G.M.; Castellares, F.; Montenegro, L.C.; de Castro, M. The beta generalized gamma distribution. Statistics 2013, 47, 888-900. [CrossRef]

8. Bourguignon, M.; Lima, M.C.S.; Leão, J.; Nascimento, A.D.C.; Pinho, L.G.B.; Cordeiro, G.M. A new generalized gamma distribution with applications. Am. J. Math. Manag. Sci. 2015, 34, 309-342. [CrossRef]

9. Prataviera, F.; Ortega, E.M.M.; Cordeiro, G.M.; Braga, A.S. The heteroscedastic odd log-logistic generalized gamma regression model for censored data. Commun.-Stat.-Simul. Comput. 2018, 48, 1815-1839. [CrossRef]

10. Ortega, E.M.M.; Bolfarine, H.; Paula, G.A. Influence diagnostics in generalized log-gamma regression models. Comput. Stat. Data Anal. 2003, 42, 165-186. [CrossRef]

11. Ortega, E.M.M.; Cancho, V.G.; Paula, G.A. Generalized log-gamma regression models with cure fraction. Lifetime Data Anal. 2009, 15, 79-106. [CrossRef]

12. Gleaton, J.U.; Lynch, J.D. Properties of generalized log-logistic families of lifetime distributions. J. Probab. Stat. Sci. 2006, 4, 51-64.

13. Cordeiro, G.M.; de Castro, M. A new family of generalized distributions. J. Stat. Comput. Simul. 2011, 81, 883-898. [CrossRef]

14. Hamedani, G.G.; Altun, E.; Korkmaz, M.Ç.; Yousof, H.M.; Butt, N.S. A new extended G family of continuous distributions with mathematical properties, characterizations and regression modeling. Pak. J. Stat. Oper. Res. 2018, 14, 737-758. [CrossRef]

15. Korkmaz, M.Ç.; Altun, E.; Yousof, H.M.; Hamedani, G.G. The odd power Lindley generator of probability distributions: properties, characterizations and regression modeling. Int. J. Stat. Probab. 2019, 8, 70-89. [CrossRef]

16. Korkmaz, M.Ç. A new family of the continuous distributions: The extended Weibull-G family. Commun. Fac. Sci. Univ. Ank. Ser. Math. Stat. 2018, 68, 248-270. [CrossRef] 
17. Korkmaz, M.Ç.; Yousof, H.M.; Hamedani, G.G.; Ali, M.M. Marshall-Olkin Generalized G Poisson Family Of Distributions. Pak. J. Stat. 2018, 34, 251-267.

18. Korkmaz, M.Ç.; Genç, A.İ. A new generalized two-sided class of distributions with an emphasis on two-sided generalized normal distribution. Commun.-Stat.-Simul. Comput. 2017, 46, 1441-1460. [CrossRef]

19. Korkmaz, M.Ç.; Alizadeh, M.; Yousof, H.M.; Butt, N.S. The generalized odd Weibull generated family of distributions: Statistical properties and applications. Pak. J. Stat. Oper. Res. 2018, 3, 541-556. [CrossRef]

20. Alizadeh, M.; Korkmaz, M.Ç.; Almamy, J.A.; Ahmed, A.A.E. Another odd log-logistic logarithmic class of continuous distributions. İstatistikçiler Derg. İstatistik Aktüerya 2018, 11, 55-72.

21. Korkmaz, M.Ç.; Yousof, H.M.; Hamedani, G.G. The exponential Lindley odd log-logistic-G family: properties, characterizations and applications. J. Stat. Theory Appl. 2018, 17, 554-571. [CrossRef]

22. Cordeiro, G.M.; Afify, A.Z.; Ortega, E.M.M.; Suzuki, A.K.; Mead, M.E. The odd Lomax generator of distributions: properties, estimation and applications. J. Comput. Appl. Math. 2019, 347, 222-237. [CrossRef]

23. Anzagra, L.; Sarpong, S.; Nasiru, S. Odd Chen-G Family of Distributions. Ann. Data Sci. 2020, 16, 1-23. [CrossRef]

24. Nagarjuna, V.B.V.; Vardhan, R.V.; Chesneau, C. Kumaraswamy generalized power Lomax distributionand its applications. Stats 2021, 4, 28-45. [CrossRef]

25. Cordeiro, G.M.; Lima, M.C.S.; Ortega, E.M.M.; Suzuki, A.K. A New Extended Birnbaum-Saunders Model: Properties, Regression and Applications. Stats 2018, 1, 32-47. [CrossRef]

26. Cordeiro, G.M.; Alizadeh, M.; Diniz Marinho, P.R. The type I half-logistic family of distributions. J. Stat. Comput. Simul. 2016, 86, 707-728. [CrossRef]

27. Alizadeh, M.; Cordeiro, G.M.; Pinho, L.G.B.; Ghosh, I. The Gompertz-G family of distributions. J. Stat. Theory Pract. 2017, 11, 179-207. [CrossRef]

28. Korkmaz, M.Ç.; Cordeiro, G.M.; Yousof, H.M.; Pescim, R.R.; Afify, A.Z.; Nadarajah, S. The Weibull Marshall-Olkin family: Regression model and application to censored data. Commun.-Stat.-Theory Methods 2019, 48, 4171-4194. [CrossRef]

29. Cordeiro, G.M.; Altun, E.; Korkmaz, M.Ç., Pescim, R.R.; Afify, A.Z.; Yousof, H.M. The xgamma Family: Censored Regression Modelling and Applications. Revstat-Stat. J. 2020, 18, 593-612.

30. Zografos, K.; Balakrishnan, N. On families of beta- and generalized gamma-generated distributions and associated inference. Stat. Methodol. 2009, 6, 344-362. [CrossRef]

31. Guerra, R.R.; Pena-Ramirez, F.A.; Cordeiro, G.M. The gamma Burr XII Distributions: Theory and applications. J. Data Sci. 2017, 15, 467-494. [CrossRef]

32. Cordeiro, G.M.; Ortega, E.M.M.; Popović, B.V. The gamma-Lomax distribution. J. Stat. Comput. Simul. 2015, 85, 305-319. [CrossRef]

33. Ramos, M.W.A.; Cordeiro, G.M.; Marinho, P.R.D.; Dias, C.R.B.; Hamedanim, G.G. The Zografos-Balakrishnan Log-Logistic Distribution: Properties and Applications. J. Stat. Theory Appl. 2013, 12, 225-244. [CrossRef]

34. Reis, L.D.R.; Cordeiro, G.M.; Lima, M.C.S. The gamma-Chen distribution: A new family of distributions with applications. Span. J. Stat. 2020, 2, 23-40. [CrossRef]

35. Castellares, F.; Lemonte, A.J. A new generalized Weibull distribution generated by gamma random variables. J. Egypt. Math. Soc. 2015, 23, 382-390. [CrossRef]

36. R Core Team. R: A Language and Environment for Statistical Computing; R Foundation for Statistical Computing: Vienna, Austria, 2020.

37. Doornik, J.A. OX: An Object-Oriented Matrix Programming Language; Timberlake Consultants and Oxford: London, UK, 2018.

38. Hashimoto, E.M.; Ortega, E.M.M.; Cordeiro, G.M.; Barreto, M.L. The log-Burr XII regression model for grouped survival data. J. Biopharm. Stat. 2012, 22, 141-159. [CrossRef]

39. Hosseini, B.; Afshari, M.; Alizadeh, M. The generalized odd gamma-G family of distributions: Properties and applications. Austrian J. Stat. 2018, 47, 69-89. [CrossRef]

40. Xu, K.; Xie, M.; Tang, L.C.; Ho, S.L. Application of neural networks in forecasting engine systems reliability. Appl. Soft Comput. 2003, 2, 255-268. [CrossRef]

41. Paranaíba, P.F.; Ortega, E.M.M.; Cordeiro, G.M.; Pescim, R.R. The beta Burr XII distribution with application to lifetime data. Comput. Stat. Data Anal. 2011, 55, 1118-1136. [CrossRef]

42. Paranaíba, P.F.; Ortega, E.M.M.; Cordeiro, G.M.; de Pascoa, M.A.R. The Kumaraswamy Burr XII distribution: Theory and practice. J. Stat. Comput. Simul. 2013, 83, 2117-2143. [CrossRef]

43. Afify, A.Z.; Cordeiro, G.M.; Ortega, E.M.M.; Yousof, H.M.; Butt, N.S. The four-parameter Burr XII distribution: Properties, regression model, and applications. Commun.-Stat.-Theory Methods 2018, 47, 2605-2624. [CrossRef]

44. Chen, G.; Balakrishnan, N. A general purpose approximate goodness-of-fit test. J. Qual. Technol. 1995, 27, 154-161. [CrossRef]

45. de Santana, T.V.F.; Ortega, E.M.M.; Cordeiro, G.M.; Silva, G.O. The Kumaraswamy-log-logistic distribution. J. Stat. Theory Appl. 2012, 11, 265-291. 